\title{
INSIDE MONEY, OUTSIDE MONEY AND SHORT TERM INTEREST RATES
}

V.V. Chari

Lawrence J. Christiano

Martin Eichenbaum

Working Paper 5269

\section{NATIONAL BUREAU OF ECONOMIC RESEARCH 1050 Massachusetts Avenue \\ Cambridge, MA 02138 \\ September 1995}

This paper is part of NBER's research programs in Economic Fluctuations and Monetary Economics. Any opinions expressed are those of the authors and not those of the National Bureau of Economic Research.

(c) 1995 by V.V. Chari, Lawrence J. Christiano and Martin Eichenbaum. All rights reserved. Short sections of text, not to exceed two paragraphs, may be quoted without explicit permission provided that full credit, including (c) notice, is given to the source. 


\title{
INSIDE MONEY, OUTSIDE MONEY \\ AND SHORT TERM INTEREST RATES
}

\begin{abstract}
This paper presents a quantitative general equilibrium model with multiple monetary aggregates. The framework incorporates a banking sector and distinguishes between $M 1$, the monetary base, currency and various measures of reserves: total, excess and non borrowed. We use a variant of the model to analyze two sets of empirical facts. The first set of facts is that different monetary aggregates covary differently with short term nominal interest rates. Broad monetary aggregates like $M 1$ and the monetary base covary positively with current and future values of short term interest rates. In contrast, the non borrowed reserves of banks covary negatively with current and future interest rates. Observations like this 'sign switch' lie at the core of recent debates about the effects of monetary policy actions on short term interest rates. According to our model, the sign switch occurs because movements in non borrowed reserves are dominated by exogenous shocks to monetary policy, while movements in the base and $M 1$ are dominated by endogenous responses to non-policy shocks. The second set of facts that we consider is that broad monetary aggregates covary positively with output. We quantify the Friedman and Schwartz hypothesis that this covariation reflects the effects of exogenous shocks to monetary policy, and the hypothesis that they reflect the endogenous response of monetary aggregates to shocks in the private economy.
\end{abstract}

V.V. Chari

Department of Economics

University of Minnesota

Minneapolis, MN 55455

Martin Eichenbaum

Department of Economics

Northwestern University

Evanston, IL 60208

and NBER
Lawrence J. Christiano

Department of Economics

Northwestern University

Evanston, IL 60208

and NBER 


\section{Introduction}

This paper presents a quantitative general equilibrium model with multiple monetary aggregates. Developing such a framework is important for answering various questions concerning the cyclical behavior of those aggregates. For example, what drives the observed positive correlation between broad monetary aggregates and output: exogenous movements in outside money, or endogenous movements in inside money? Why do different monetary aggregates covary differently with short-term interest rates? To make progress on these questions, we need a model that distinguishes between different monetary aggregates. This paper takes a modest step towards developing such a model.

The framework presented here incorporates a banking sector and distinguishes between M1, the monetary base, currency and various measures of bank reserves: total, excess and non borrowed. The key features of our model that distinguish it from standard real business cycle models are as follows. First, households have a technology that allows them to use currency and demand deposits to economize on time spent purchasing consumption goods. Second, there is a banking sector that produces loans and demand deposits using capital, labor and reserves. Third, the monetary authority controls the monetary base while the private sector determines the composition of the base between currency and bank reserves.

We use a variant of our model to discuss the following phenomenon: broad monetary aggregates like M1 and the base covary positively with current and future values of short term interest rates, while the opposite is true for non borrowed reserves. This 'sign switch' is interesting because it lies at the core of recent debates about the effects of monetary policy 
actions on short term interest rates. Analysts who focused on broader monetary aggregates tended to conclude that exogenous monetary injections drive short term rates up. Analysts who focused on non borrowed reserves tended to reach the opposite conclusion (see Christiano (1995) for a review.) The interesting question is: how can we account for both phenomena simultaneously? The answer embedded in our model is that movements in non borrowed reserves are dominated by exogenous shocks to monetary policy, while movements in the base and $M 1$ are dominated by endogenous responses to non-policy shocks.

To articulate this argument, we need a model with the following features. First, it must allow for several types of shocks. We take the simplest possible approach, by allowing for two shocks: exogenous shocks to the growth rate of the monetary base and exogenous shocks to technology. Second, the model must allow for broad monetary aggregates to respond to non-policy shocks. This happens in our model because the banking sector expands after a technology shock to the goods producing sector. Since these shocks also have the effect of raising equilibrium interest rates, the model can account for the observed positive correlation between $M 1$ and interest rates. Third, to account for the positive relation between the monetary base and interest rates we take a particular stand on Federal reserve monetary policy. We assume that innovations to the growth rate of the monetary base are composed of two components. One component is purely exogenous, while the other reacts to contemporaneous innovations in technology. We identify the former with innovations to the non borrowed component of the monetary base. We identify the latter with innovations in borrowed reserves. These assumptions reflect our view that in the data innovations to non borrowed reserves are dominated by exogenous shocks to policy while innovations to borrowed reserves primarily reflect the response of discount window borrowing to non-policy 
shocks. It is this reactive component of innovations to the base that allows the model to account for the observed positive correlation between the base and the interest rate. ${ }^{1}$

Fourth, our model must incorporate elements which imply that non borrowed reserves covary negatively with the interest rate. We accomplish this in part by including features which ensure that exogenous policy shocks to the base generate important liquidity effects. The key assumption that we make is that households cannot change their currency holdings immediately after shocks in their environment. ${ }^{2}$ It follows that an expansionary open market operation leads to a rise in the ratio of total bank reserves to the base. ${ }^{3}$ As long as this ratio remains high, a subset of the agents in the economy - banks and firms - must hold a disproportionate share of the base and there will be a liquidity effect associated with an open market operation. The liquidity effect persists until households have fully adjusted their currency holdings. In our model this effect is sufficiently strong and persistent to imply that a positive shock to the base leads to a persistent decline in interest rates.

The assumption that currency holdings do not instantly respond to shocks, together with our specification of monetary policy, guarantees that innovations to non borrowed reserves coincide exactly with innovations to the exogenous component of monetary policy. This result would not hold if currency holdings immediately responded to shocks in the base. For example, a positive innovation to technology could in principle trigger a positive innovation in non borrowed reserves if it generated a contemporaneous fall in currency holdings. Similarly, an exogenous $\$ 1$ increase in the monetary base could generate less than a $\$ 1$ increase in non borrowed reserves if it triggered a contemporaneous rise in currency holdings by the public.

Though innovations to non borrowed reserves reflect only exogenous policy shocks to the base, non borrowed reserves are nevertheless endogenous in our model because they respond 
to all shocks with a delay. Still, our assumptions are enough to guarantee that movements in non borrowed reserves are quantitatively dominated by exogenous monetary policy shocks. We presume that our basic results would also obtain if innovations to the non borrowed component of the base contained a contemporaneous reactive component. ${ }^{4}$ Allowing for this possibility would considerably complicate our model, but would not change the essence of the argument, as long as innovations to non borrowed reserves were dominated by exogenous policy shocks.

In sum, our model accounts for the positive co-movements between the base, $M 1$ and the interest rate as reflecting the importance of shocks to the demand for money (stemming, in our analysis, from technology shocks), the ability of the banking system to produce inside money, and the nature of monetary policy. It accounts for the negative co-movements between non borrowed reserves and the interest rate as reflecting the importance of liquidity effects in the monetary transmission mechanism.

Our model also articulates one answer to the question of what drives the observed positive correlation between broader monetary aggregates and output. Consistent with arguments in King and Plosser (1984), the model attributes these correlations to the effects of non-policy shocks on money, rather than the effects of monetary policy shocks on output. Specifically, in the model, output is positively correlated with the base and $M 1$. This result reflects the weak magnification and propagation effects of monetary policy shocks in the model.

The remainder of this paper is organized as follows. In section 2 we summarize some key facts regarding the dynamic co-movements between different monetary aggregates, output and the federal funds rate. Section 3 presents the model. Section 4 reports its quantitative properties. Finally, section 5 contains some concluding remarks. 


\section{Some Basic Facts}

In this section we briefly summarize some basic facts about the dynamic comovements between the federal funds rate, real GNP and different monetary aggregates. These facts motivate the model of section 3 by documenting the sign 'switch' and lead - lag relationships between money and output discussed in the introduction.

We consider three monetary aggregates: non borrowed reserves, NBR (CITIBASE mnemonic FMRNBC), the base, $M 0$ (FMBASE), and $M 1$ (FM1). In addition we use data on the federal funds rate, $F F$ (FYFF) and real $G D P, Y$ (GDP). The (quarterly) time series on all these variables display pronounced trends over the sample period 1959:1 - 1992:4. Consequently, some stationarity-inducing transformation of the data must be adopted. Here we work with the filter developed by Hodrick and Prescott (1980). Specifically, all of the statistics discussed in this section pertain to variables which have been logged and processed via the Hodrick and Prescott (HP) filter.

Figure 1 presents our point estimates of $\rho\left(M 1_{t}, F F_{t-\tau}\right), \rho\left(M 0_{t}, F F_{t-\tau}\right)$ and $\rho\left(N B R_{t}\right.$, $\left.F F_{t-\tau}\right), \tau=-6, \ldots, 6$, where $\rho$ denotes the correlation operator. The solid lines in Figure 1 denote point estimates of the correlations while the dashed lines correspond to a one standard deviation band about the point estimates.

Consider first the results for non borrowed reserves. Notice that there is a strong, statistically significant negative contemporaneous correlation (-.54) between $F F_{t}$ and $N B R_{t}$. Also note that $F F_{t}$ is negatively correlated with leads and lags of $N B R_{t}$ up to one year. ${ }^{5}$ The key thing to notice about the correlations involving $M 0$ and $M 1$ is how different they 
are from those involving non borrowed reserves. In particular, neither $M 0$ nor $M 1$ displays a significant contemporaneous correlation with $F F_{t}$. Moreover both are positively correlated with future values of $F F_{t}$ but negatively correlated with lagged values of $F F_{t}$. It is clear then that non borrowed reserves covary quite differently with the federal funds rate than does $M 1$. The term 'sign switch' is a short hand way of summarizing the main difference: non borrowed reserves are negatively correlated with current and future values of the federal funds rate while the opposite is true for $M 0$ and $M 1$. Based on these correlations, it is perhaps not surprising that analysts working with $M 0$ and $M 1$ conclude that innovations in these monetary aggregates lead to a rise in interest rates while analysts working with $N B R$ conclude the opposite.

Figure 2 presents our point estimates of $\rho\left(N B R_{t}, Y_{t-\tau}\right), \rho\left(M 0_{t}, Y_{t-\tau}\right)$ and $\rho\left(M 1_{t}, Y_{t-\tau}\right)$, $\tau=-6, \ldots, 6$. Notice that both $M 0$ and $M 1$ display a strong positive correlation with real GDP (0.34 and 0.29 , respectively). In contrast, $N B R$ is negatively correlated with current real GDP $\left(\rho\left(N B R_{t}, Y_{t}\right)=-0.22\right)$. Nevertheless all three monetary aggregates lead real GDP in that they are positively correlated with future values of $Y_{t}$. This basic fact (at least regarding $M 0$ and $M 1$ ) has been stressed by a variety of authors. Friedman and Schwartz (1963), among others, cite it as evidence that monetary policy has been an important source of aggregate output fluctuations. King and Plosser (1984) argue that the key to interpreting this fact lies in the endogeneity of money. Sources of endogeneity in broad monetary aggregates like $M 1$ include the response of the banking system and the Federal Reserve's discount window to shifts in the demand for money, say because of technology shocks. The model of section 3 allows for both endogenous and exogenous sources of positive comovements between monetary aggregates and output. 
Finally Figure 3 presents our point estimates of $\rho\left(F F_{t}, Y_{t-\tau}\right), \tau=-6, \ldots, 6$. Notice that $F F_{t}$ is positively correlated with $Y_{t}$ but negatively correlated with future values of $Y_{t}$. This is consistent with the well-known observation that interest rates tend to be at their highest level at the peak of the business cycle. So a high level of the time $t$ interest rate is associated with lower future values of real output. This is reflected in the fact that $F F_{t}$ displays a sharp negative correlation with current and future growth rates of output $\left(\rho\left(F F_{t}, \Delta Y_{t}\right)=-.33\right)$ and $\left.\rho\left(F F_{t}, \Delta Y_{t+1}\right)=-.52\right)$. In conjunction with the recent VAR literature aimed at studying the dynamic effects of exogenous shocks to monetary policy, these findings provide strong motivation for developing monetary business cycle models. ${ }^{6}$ 


\section{The Model}

We consider a two sector economy that is populated by a large number of infinitely lived households. The first sector produces a good that can be consumed or invested as capital. The second sector consists of banks who produce demand deposits for households and make loans for working capital and investment purchases. Households supply labor and capital to both sectors. In addition they purchase consumption goods using a 'shopping time technology' that allows households to economize on shopping time by the use of currency and demand deposits. Analogously to limited participation models of the sort considered by Lucas (1990), Fuerst (1992) and Christiano and Eichenbaum (1995), we assume that, each period, households allocate their nominal assets between currency and interest bearing deposits at banks. These deposits along with deposits arising from cash injections by the monetary authority constitute the reserves of the banking sector.

\section{The Goods Producing Firm: Technology and Choice Problem}

The technology for producing new goods is given by:

$$
y_{t}=f\left(k_{f t}, n_{f t}, l_{f t}, x_{f t}, z_{t}\right)=a_{f} x_{f t} l_{f t} k_{f t}^{\alpha}\left(z_{t} n_{f t}\right)^{1-\alpha}
$$

where $a_{f}$ is a positive scalar, $0<\alpha<1$ while $k_{f t}, n_{f t}$ and $l_{f t}$ denote time $t$ units of capital, number of persons working and the length of the workweek in the goods producing sector, respectively. The economy wide technology parameter, $z_{t}$, evolves according to

$$
z_{t}=\exp \left(\mu_{z} t\right)
$$


where $\mu_{z}>0$. The sector specific technology parameter, $x_{f t}$, evolves according to

$$
x_{f t}=x_{f t-1}^{\rho_{f}} \exp \left(\epsilon_{f t}\right),
$$

where $0<\rho_{f}<1$ and $\epsilon_{f t}$ is a mean zero, i.i.d. shock to the production technology which has standard deviation, $\sigma_{f}$. The output of this sector can either be consumed or invested to augment the capital stock.

According to (1), output is linear in the workweek. This reflects our assumption that the flow of services from capital and from persons employed is proportional to the length of the workweek. ${ }^{7}$ Perfectly competitive firms produce output using the technology given by (1) - (3). By assumption, all inputs (labor and capital services) must be paid in advance of production. These payments are financed by working capital loans from banks. Funds from the bank loans are made available to firms in the form of checking accounts. For each dollar that the firm borrows, it must repay $\left(1+r_{f t}\right)$ dollars at the end of the period after the consumption good market closes. These repayments are net of any interest earned on the checking account associated with the loan, i.e. $r_{f t}$ is net of the time $t$ interest rate on checking accounts.

The firm maximizes time $t$ profits:

$$
P_{t} f\left(k_{f t}, n_{f t}, l_{f t}, x_{f t}, z_{t}\right)-\left(1+r_{f t}\right) r_{k t} P_{t} k_{f t}-\left(1+r_{f t}\right) W_{t}\left(l_{f t}\right) n_{f t}
$$

by choice of $k_{f t}, n_{f t}$ and $l_{f t}$ subject to (1) taking as given the nominal wage function, $W_{t}\left(l_{f t}\right)$. The variables $P_{t}$ and $r_{k t}$ denote the time $t$ price level and rental rate on capital, respectively. The firm is owned by the representative household which receives any profits at the end of the period. However, given our assumptions, profits will be zero in equilibrium. 
The first order conditions to the firm's problem are given by

$$
\begin{gathered}
f_{k t}=\left(1+r_{f t}\right) r_{k t}, \\
f_{n t}=\left(1+r_{f t}\right) W_{t}\left(l_{f t}\right) / P_{t},
\end{gathered}
$$

and

$$
f_{l t}=\left(1+r_{f t}\right) W_{t}^{\prime}\left(l_{f t}\right) n_{f t} / P_{t}
$$

Here $W_{t}^{\prime}\left(l_{f t}\right)$ denotes the derivative of $W_{t}\left(l_{f t}\right)$, while $f_{k t}, f_{n t}$ and $f_{l t}$ denote the time $t$ marginal products of capital, persons employed and the length of the workweek in the goods producing sector, respectively. Notice that the firm equates the time $t$ marginal product of the different factors of production to their marginal costs, inclusive of financing costs.

\section{Banks: Technology and Choice Problem}

As in Lucas (1993), we assume that there is a technology for producing demand deposits. This technology is given by,

$$
h\left(k_{b t}, n_{b t}, l_{b t}, e_{t}, z_{t}\right)=a_{b}\left[l_{b t} k_{b t}^{\alpha}\left(z_{t} n_{b t}\right)^{1-\alpha}\right]^{\xi} e_{t}^{1-\xi}
$$

where $a_{b}$ is a positive scalar, $0<\xi<1$, while $k_{b t}, n_{b t}$ and $l_{b t}$ denote time $t$ units of capital, number of persons working and the length of the workweek in the banking sector, respectively. ${ }^{8}$ The variable $e_{t}$ denotes the real value of time $t$ excess reserves. Including $e_{t}$ in (8) is a tractable way of ensuring that excess reserves are always non negative. Since $e_{t}$ is productive, the banking sector can expand deposits immediately in response to shocks to the private economy that are not accommodated by the monetary authority. Moreover, the fact that $e_{t}$ is endogenous implies that the money multipliers - the ratios of the broader monetary aggregates to total reserves - are endogenous too. 
Next we consider the determination of banks reserves and loans. Cash reserves flow to the bank from two sources. At the beginning of the period, before the date $t$ shocks are realized, households deposit $A_{t}$ dollars in banks. In addition, during the period, the monetary authority debits or credits households' checking accounts with $X_{t}$ dollars. Consequently, the total time $t$ cash reserves of the banking system equals $A_{t}+X_{t}$. Banks' other time $t$ assets consist of loans to finance firms' working capital needs and loans for new investment purchases. Consequently, total time $t$ loans, $S_{t}$, are given by,

$$
S_{t}=W_{t}\left(l_{f t}\right) n_{f t}+W_{t}\left(l_{b t}\right) n_{b t}+r_{k t} P_{t} K_{t}+P_{t} I_{t}
$$

where $K_{t}=K_{f t}+K_{b t}$ and $I_{t}$ denotes time $t$ investment.

The total time $t$ assets of the banking system are equal to its reserves plus outstanding loans, $A_{t}+X_{t}+S_{t}$. When a bank makes a loan, it sets up a checking account for the amount of the loan. We adopt the convention that loans are not used until the end of the period. Since the bank's only liabilities are its demand deposits, $D_{t}$, and these must equal total assets, we have that

$$
D_{t}=A_{t}+X_{t}+S_{t}
$$

The monetary authority imposes a reserve requirement that banks must hold at least a fraction $\tau$ of their demand deposits in the form of reserves. Therefore, nominal excess reserves, $E_{t}$, are given by

$$
E_{t}=A_{t}+X_{t}-\tau D_{t}
$$

These must satisfy the constraint $E_{t} \geq 0$. The Inada conditions on the production function for demand deposits, (8), imply that this constraint are never binding. 
The bank's earnings on loans, net of the interest paid on the underlying checking accounts, are $r_{f t} S_{t}$, while interest payments on reserves owned by the household are $r_{a t}\left(A_{t}+X_{t}\right)$. Since the bank's operating costs are $\left(1+r_{f t}\right) r_{k t} P_{t} k_{b t}+W_{t}\left(l_{b t}\right)\left(1+r_{f t}\right) n_{b t}$, its time $t$ profits are,

$$
F_{t}=r_{f t} S_{t}-r_{a t}\left(A_{t}+X_{t}\right)-\left(1+r_{f t}\right) r_{k t} P_{t} k_{b t}-\left(1+r_{f t}\right) W_{t}\left(l_{b t}\right) n_{b t}
$$

The banks maximizes (12) by choice of $A_{t}, S_{t}, k_{b t}, l_{b t}, n_{b t}$ and $e_{t}$ subject to (8) - (11). These decisions are made after the realization of all time $t$ shocks.

As we mentioned above, households choose $A_{t}$ before the realization of the time $t$ shocks. Banks choose $A_{t}$ after the time $t$ shocks are realized. There is an inter bank reserve market in which banks can trade reserves. The equilibrium interest rate $r_{a t}$ in this market adjusts so that, for each realization of the time $t$ shocks, the net demand for reserves is equal to the level of $A_{t}$ chosen by households, plus $X_{t}$.

Using (9) and (11) to eliminate $S_{t}$ and $e_{t}$ from (12), we obtain the following first order conditions:

$$
\begin{gathered}
\left(1+r_{f t}\right) r_{k t}=\frac{h_{k t}}{\left(1+\tau h_{e t}\right)} r_{f t} \\
\frac{\left(1+r_{f t}\right) W_{t}\left(l_{b t}\right)}{P_{t}}=\frac{h_{n t}}{\left(1+\tau h_{e t}\right)} r_{f t} \\
\frac{\left(1+r_{f t}\right) W_{t}^{\prime}\left(l_{b t}\right) n_{b t}}{P_{t}}=\frac{h_{l t}}{\left(1+\tau h_{e t}\right)} r_{f t} \\
r_{a t}=\frac{h_{e t}(1-\tau)-1}{\left(1+\tau h_{e t}\right)} r_{f t} .
\end{gathered}
$$

Here $h_{k t}, h_{n t}, h_{l t}$ and $h_{e t}$ denote the time $t$ marginal products of capital, persons, the length of the workweek and real excess reserves in producing demand deposits.

To provide intuition for these first order conditions, use (8), (9) and (10) to consolidate the constraints on the bank's problem as 


$$
\frac{A_{t}+X_{t}+S_{t}}{P_{t}}=h\left(k_{b t}, n_{b t}, l_{b t}, \frac{A_{t}+X_{t}-\tau\left(A_{t}+X_{t}+S_{t}\right)}{P_{t}}, \tilde{z}_{t}\right) .
$$

Totally differentiating (17) we obtain:

$$
\begin{gathered}
\frac{\partial S_{t} / \partial k_{b t}}{P_{t}}=\frac{h_{k t}}{\left(1+\tau h_{e t}\right)}, \\
\frac{\partial S_{t} / \partial n_{b t}}{P_{t}}=\frac{h_{n t}}{\left(1+\tau h_{e t}\right)} \\
\frac{\partial S_{t} / \partial l_{b t}}{P_{t}}=\frac{h_{l t}}{\left(1+\tau h_{e t}\right)} \quad \text { and } \\
\partial S_{t} / \partial A_{t}=\frac{(1-\tau) h_{e t}-1}{1+\tau h_{e t}} .
\end{gathered}
$$

Abstracting from reserve requirements, if the bank has one more unit of capital it can increase total real loans by $h_{k t}$. But with reserve requirements, when a bank increases loans by $\$ 1$, required reserves rise by $\$ \tau$ so that excess reserves fall by $\$ \tau$. Because excess reserves are productive, other things equal, total loans must fall by $\tau h_{e t}$. When capital is used to create a loan this effect must be taken int $n$ account. Consequently, the net increase in securities, $\frac{\partial S_{t} / \partial K_{b t}}{P_{t}}$, equals $\frac{h_{k t}}{\left(1+\tau h_{t \ell}\right)}$. The Euler equation for capital (13) equates the marginal cost of an extra unit of capital $\left(1+r_{f t}\right) r_{k t}$ to the marginal revenue generated by the extra unit of capital, $\frac{\partial S_{t} / \partial K b_{t}}{P_{t}} r_{f t}$. Similar intuition applies to the Euler equations for $n_{b t}$ and $l_{b t}$. Finally consider the expression $\partial S_{t} / \partial A_{t}$. A dollar increase in cash obtained via a unit increase in $A_{t}$ generates a demand deposit liability of $\$ 1$ and a net increase in excess reserves of $\$(1-\tau)$. Given our technology, this allows total demand deposits to increase by $\$(1-\tau) h_{e t}$. Since the initial increase in cash generated a demand deposit liability of $\$ 1$, total loans can increase by $\$(1-\tau) h_{e t}-1$. Recall though that for every dollar increase in loans, required reserves rise by $\$ \tau$ so that excess reserves fall by $\$ \tau$. Taking this effect into account, the total increase in 
loans generated by an initial increase in $A_{t}, \partial S_{t} / \partial A_{t}$ equals $\frac{(1-\tau) h_{e t}-1}{1+\tau h_{e t}}$. The Euler equation for $A_{t}$, (16), equates, $r_{a t}$, the marginal cost of an extra unit of $A_{t}$, to $\frac{\partial S_{t} / \partial A_{t}}{P_{t}} r_{f t}$, the marginal revenue generated by the extra unit of cash.

Note that our formulation of the banking sector is similar, in many respects, to the banking models in standard money and banking textbooks, e.g. Mishkin (1992). Suppose we drop the production function for demand deposits (8) from the analysis. Then the constraint on excess reserves, $E_{t} \geq 0$, would hold with strict equality in equilibrium. In that event, a one dollar cash injection (i.e. a one unit increase in $X_{t}$ ) would raise demand deposits by $\$ 1 / \tau$ if currency held by the public did not change. This corresponds to the simplest money multiplier considered in undergraduate textbooks.

\section{The Household}

The representative household ranks alternative streams of consumption and leisure using the criterion function

$$
E_{0}\left\{\sum_{t=0}^{\infty} \beta^{t}\left[n_{t} U\left(C_{t}^{e}, L_{t}^{e}\right)+\left(1-n_{t}\right) U\left(C_{t}^{u}, L_{t}^{u}\right)\right]\right\}
$$

Here $n_{t}$ is the probability of being employed, $C_{t}^{e}$ denotes time $t$ consumption if employed, $L_{t}^{e}$ denotes time $t$ leisure if employed, $C_{t}^{u}$ denotes time $t$ consumption if unemployed, $L_{t}^{u}$ denotes time leisure if unemployed and $E_{0}$ denotes the expectations operator conditional on the household's information set at the beginning of time 0 . Below we discuss agents' information sets in greater detail. We assume that the period utility function is given by

$$
U(C, L)=\left(C L^{\gamma}\right)^{\psi} / \psi
$$

where $\psi<1, \gamma \psi<1$, and $(1+\gamma) \psi<1$. We normalize the household's time endowment to be 1. The household divides its time endowment into leisure, hours worked in the market 
place, $l_{1 t}$, if a job is found, time spent acquiring consumption goods, $l_{2 t}$, and time spent searching for employment, $l_{3 t}{ }^{9}$

The technology involving $l_{2 t}$ is motivated by ideas in McCallum and Goodfriend (1987) and Lucas (199:3). In particular, we suppose that households use currency, demand deposits and time to purchase consumption goods. The amount of time used, $l_{2 t}$, is an increasing function of $C_{t}$, and a decreasing function of both real currency, $M_{t} / P_{t}$, and real demand deposits $D_{h t} / P_{t}$. Here $M_{t}$ and $D_{h t}$ denote the time $t$ nominal values of currency and demand deposits, respectively. The transactions technology is given by

$$
l_{2 t}=J\left[\left(\frac{P_{t} C_{t}}{M_{t}}\right)^{\theta}\left(\frac{P_{t} C_{t}}{D_{h t}}\right)^{1-\theta}\right],
$$

where $J$ and $\theta$ are non negative scalars.

The search technology is given by,

$$
l_{3 t}=\nu_{0} n_{t}^{\nu_{1}}
$$

where $\nu_{0}$ and $\nu_{1}$ are non negative scalars. The basic idea here is that spending more time on search raises the probability of finding employment.

We now consider the choice problem of the representative household. In our quantitative work we assume that there are adjustment costs associated with changing currency holdings between periods. For expositional reasons, we suppress these adjustment costs for now. This allows us to display the basic intuition underlying the household's Euler equation in a way that preserves on notation. In the next subsection we explicitly describe the adjustment cost technology.

We assume that there are perfect markets to insure households against the idiosyncratic risk of not finding a job. In addition we assume that the time devoted by the household to 
finding a job, $l_{3 t}$, is observable. This implies that households receive labor income $W_{t}\left(l_{1 t}\right) n_{t}$ if they choose a workweek of length, $l_{1 t}$, and a probability of finding a job $n_{t}$. Notice that with this specification, households which are identical ex ante in their labor market decisions receive the same income regardless of whether they are successful in finding a job.

Total household demand deposits are given by

$$
D_{h t}=A_{t}+X_{t}+W_{t}\left(l_{1 t}\right) n_{t}+r_{k t} P_{t} K_{t}
$$

According to relation (22), households' demand deposits consist of cash that households deposit at the bank at the beginning of the period plus wage income and the rental income from capital. The last two sources of funds are directly deposited into their checking accounts. Recall our convention that firms draw on loans at the end of the period. So, households receive wage and rental income at the end of the period and do not receive interest on these funds. However they are available as inputs into the transactions technology.

The household's end of period $t$ flow budget equation is given by

$$
P_{t} C_{t}+Q_{t+1}+\left(1+r_{f t}\right) P_{t} I_{t} \leq\left(1+r_{a t}\right)\left(A_{t}+X_{t}\right)+W_{t}\left(l_{1 t}\right) n_{t}+r_{k t} P_{t} K_{t}+M_{t}+F_{t}
$$

Here $F_{t}$ denotes lump sum dividends equal to the time $t$ profits of the representative banking firm. The variable $Q_{t}$ denotes beginning of period $t$ nominal assets. These must be allocated between currency, $M_{t}$, and demand deposits, $A_{t}$ :

$$
Q_{t}=M_{t}+A_{t}
$$

\section{Information Sets and the Household's Decisions}

In order for the household's problem to be well defined, we need to specify the information set upon which its decisions are made. To this end, let $\Omega_{t}$ denote the history of all shocks up 
to the end of time $t$, not including the time $t$ realizations of idiosyncratic shocks indicating whether a given household has found employment. Let $\Omega_{t}^{1}$ denote the union of $\Omega_{t}$ and the idiosyncratic employment shock.

The household's problem is to maximize (18) subject to (20) - (24) by choice of contingency plans for $\left\{C_{t}, Q_{t+1}, K_{t+1}, l_{1 t}, l_{2 t}, l_{3 t}, n_{t}, M_{t}, A_{t}: t \geq 0\right\}$. We assume that the household must divide its beginning of period nominal assets between currency and demand deposits before the realization of any time $t$ shocks, so that $M_{t}$ and $A_{t}$ are functions only of $\Omega_{t-1}^{1}$. The household's other choice variables are functions of $\Omega_{t}$. The assumption that household consumption, investment and shopping time are independent of the realization of idiosyncratic employment uncertainty is motivated by a desire to minimize the complexity of the model.

It is convenient to define

$$
\widetilde{U}_{c t}=U_{c t}+U_{l t} \frac{l_{2 t}}{C_{t}}, U_{l t}^{e}=U_{l t} \text { if employed, and } U_{n t}=U_{l t} v_{0} v_{1} n_{t}^{\left(v_{1}-1\right)}
$$

where $U_{l t}$ denotes the time $t$ partial derivative of utility with respect to labor. The variable, $\tilde{U}_{c t}$, denotes the 'effective' marginal utility of consumption obtained after using the transaction technology function (20) to substitute $l_{2 t}$ out of the utility function. The first order necessary conditions for the household's choice of $K_{t+1}, l_{1 t}, n_{t}, M_{t}$ and $A_{t}$ are given by:

$$
\begin{gathered}
E\left[\begin{array}{c}
\left(1+r_{f t}\right) \tilde{U}_{c t}-\beta \tilde{U}_{c t+1}\left(r_{k t+1}+(1-\delta)\left(1+r_{f t+1}\right)\right) \\
-\beta U_{1 t+1}(\theta-1) \frac{l_{2 t+1}}{D_{h t+1}} r_{k t+1} P_{t+1} \mid \Omega_{t}
\end{array}\right]=0 \\
E\left[\left(\tilde{U}_{c t} W_{t}^{\prime}\left(l_{1 t}\right) n_{t} / P_{t}-U_{l t} \frac{(1-\theta) l_{2 t}}{D_{h t}} W_{t}^{\prime}\left(l_{1 t}\right) n_{t}\right) \mid \Omega_{t}\right]+n_{t} U_{l t}^{e}=0 \\
E\left[\left(\tilde{U}_{c t} W_{t}\left(l_{1 t}\right) / P_{t}-U_{l t} \frac{(1-\theta) l_{2 t}}{D_{h t}} W_{t}\left(l_{1 t}\right)+U_{n t}\right) \mid \Omega_{t}\right]+U_{t}^{e}-U_{t}^{l}=0 \\
E\left[\left(\tilde{U}_{c t} / P_{t}-\beta \tilde{U}_{c t+1} / P_{t+1}+\beta \theta U_{l t+1} \frac{l_{2 t+1}}{M_{t+1}}\right) \mid \Omega_{t-1}^{1}\right]=0
\end{gathered}
$$




$$
E\left[\left(r_{a t} \widetilde{U}_{c t} / P_{t}+U_{l t}\left[\frac{\theta l_{2 t}}{M_{t}}-\frac{(1-\theta) l_{2 t}}{D_{h t}}\right]\right) \mid \Omega_{t-1}^{1}\right]=0
$$

To understand (25), suppose that, relative to the optimal plan, the household increased $K_{t+1}$ by one unit, adjusted $C_{t}$ and $C_{t+1}$ by the appropriate amounts and left $K_{t+2}$ unaffected. Since investment must be financed with bank loans, to increase $K_{t+1}$ by one unit, the household must reduce $C_{t}$ by $\left(1+r_{f t}\right)$ units. The first term on the left hand side of $(25)$ equals the time $t$ effective utility cost associated with this change. On the benefits side, an extra unit of $K_{t+1}$ directly raises $C_{t+1}$ by $r_{k t+1}$ units. To keep $K_{t+2}$ unaffected, the household must reduce $I_{t+1}$ by $(1-\delta)$ units. This generates an additional increase in $C_{t+1}$ of $\left(1+r_{f t+1}\right)(1-\delta)$ units. The expected utility be.tefits of this increase is given by the second term in (25). Next note that the increase in $K_{t+1}$ generates additional dollar income at time $t+1$ of $r_{k t+1} P_{t+1}$ which is deposited in the household's checking account. The third term in (25) gives the expected utility benefits of the resulting decrease in $l_{2 t}$. Along the optimal plan, the expected benefits of the proposed perturbation must equal the expected costs which yields (25).

To understand (26), suppose that, relative to the optimal plan, the household works one more unit of time in the market place and consumes the proceeds. There are two returns associated with this action. First, there is the effective utility gain in consumption, given by the first term on the left hand side of (26). Second, recall that wage payments are credited to household's checking accounts. Because of the assumed transactions technology, these payments reduce time spent transacting. The utility value of this reduction is given by the second term on the left hand side of (26). This action results in a loss in leisure, the utility value of which is given by the last term on the left hand side of (26). The intuition for (27) is similar to that underlying (26). 
To understand (28) suppose that, relative to the optimal plan, the household spends one dollar less on time $t$ consumption, increases its holding of $M_{t+1}$ and then spends that dollar on time $t+1$ consumption. The first term on the left hand side of (28) gives the time $t$ effective utility loss associated with this action. The second term on the left hand side of (28) gives the effective utility gain associated with increasing consumption by $1 / P_{t+1}$ units. The tl.ird term on the left hand side reflects the utility gain associated with the reduction in $l_{2 t+1}$ that occurs because $M_{t+1}$ has been raised by one dollar.

To understand (29), suppose that, relative to the optimal plan, the consumer reduces $M_{t}$ by one unit, increases $A_{t}$ and spends the dollar to increase $C_{t+1}$. The net increase in $Q_{t+1}$ due to the reallocation is $r_{a t}$. Viewed from the perspective of time $t$, the utility value of these extra dollars equals $\beta E\left\{r_{a t}\left(\tilde{U}_{c t+1} / P_{t+1}-\theta U_{l t+1} \frac{l_{2 t+1}}{M_{t+1}}\right) \mid \Omega_{t-1}^{1}\right\}$. From (28), this equals the first term on the left hand side of (29). Given our transactions technology, the net effect on $l_{2 t}$ equals $\frac{\theta l_{2 t}}{M_{t}}-\frac{(1-\theta) l_{2 t}}{D_{h t}}$. The utility value of this change in $l_{2 t}$ is given by the second term on the left hand side of (29).

\section{Allowing for Adjustment Costs}

The key friction embedded in our model is the assumption that $M_{t}$ and $A_{t}$ are chosen before households observes the $t$ shocks to the economy. This formulation of the friction corresponds to the assumption that it is infinitely costly for households to adjust their currency holdings within the period but costless to adjust them between periods. Formulating the friction in this manner has an important disadvantage. As in Lucas (1990), Fuerst (1992) and Christiano and Eichenbaum (1995), the liquidity effects associated with a monetary policy shock last only one period. To generate persistent liquidity effects, we extend our baseline 
specification and suppose that there are adjustment costs associated with changing currency holdings between periods. In a precise sense to be defined below, very small adjustment costs render the model consistent with the notion that positive monetary policy shocks lead to persistent declines in short term interest rates.

We suppose that adjustment costs are denominated in units of labor, $l_{4 t}$. Recall that the portfolio decision facing households is how to divide $Q_{t}$ between $M_{t}$ and $A_{t}$. We adopt the following adjustment cost technology which penalizes changes in $M_{t} / M_{t-1}$ :

$$
l_{4 t}=\kappa\left(M_{t}, M_{t-1}\right)=\Lambda_{1}\left\{\exp \left[\Lambda_{2}\left(\frac{M_{t}}{M_{t-1}}-f\right)\right]+\exp \left[-\Lambda_{2}\left(\frac{M_{t}}{M_{t-1}}-f\right)\right]-2\right\} .
$$

Here $\Lambda_{1}, \Lambda_{2}$, and $f$ are non negative constants. The parameter $f$ is set so that level and marginal adjustment costs are zero in steady state.

The presence of adjustment costs requires that we change the Euler equations for $M_{t}$ and $A_{t}$. Specifically, (28) and (29) are replaced by,

$$
\begin{gathered}
E\left[\begin{array}{c}
\left(\widetilde{U}_{c t} / P_{t}-\beta \tilde{U}_{c t+1} / P_{t+1}+\beta \theta U_{l t+1} \frac{l_{2 t+1}}{M_{t+1}}\right) \\
-\beta U_{l+1} \kappa_{1}\left(M_{t+1}, M_{t}\right)+\beta^{2} U_{l t+2} \kappa_{2}\left(M_{t+2}, M_{t+1}\right) \mid \Omega_{t-1}
\end{array}\right]=0 \\
E\left[\left(\begin{array}{c}
r_{a t} \widetilde{U}_{c t} / P_{t}+U_{l t}\left[\frac{\theta l_{2 t}}{M_{t}}-\frac{(1-\theta) l_{2 t+1}}{D_{h t}}\right] \\
-U_{l t} \kappa_{1}\left(M_{t}, M_{t-1}\right)+\beta U_{l t+1} \kappa_{2}\left(M_{t+1}, M_{t}\right)
\end{array}\right) \Omega_{t-1}\right]=0
\end{gathered}
$$

Here $\kappa_{1}$ and $\kappa_{2}$ denote the derivatives of the $\kappa$ function with respect to its first and second arguments, respectively.

\section{Equilibrium}

Define the allocation functions $M_{t}\left(\Omega_{t-1}\right), A_{t}\left(\Omega_{t-1}\right), C_{t}\left(\Omega_{t}\right), Q_{t+1}\left(\Omega_{t}\right), K_{t+1}\left(\Omega_{t}\right), l_{1 t}\left(\Omega_{t}\right)$, $l_{2 t}\left(\Omega_{t}\right), l_{3 t}\left(\Omega_{t}\right), l_{4 t}\left(\Omega_{t}\right), n_{t}\left(\Omega_{t}\right)$ and the price functions $r_{f t}\left(\Omega_{t}\right), r_{a t}\left(\Omega_{t}\right), r_{k t}\left(\Omega_{t}\right), W_{t}\left(\Omega_{t}\right), p_{t}\left(\Omega_{t}\right)$

A competitive equilibrium is a collection of allocation and price functions such that (i) the allocation functions solve the maximization problem of the household, the banking firm 
and the goods producing firm, and (ii) all markets clear. In the goods market this requires

$$
C_{t}+K_{t+1}-(1-\delta) K_{t}=f\left(k_{f t}, n_{f t}, l_{f t}, x_{f t}, z_{t}\right)
$$

Non borrowed Reserves, Total Reserves, the Base, M1 and Monetary Policy

We conclude this section by (i) summarizing the monetary variables in our model, and their relationship to various monetary aggregates in the data, and (ii) discussing our assumptions about monetary policy.

The broadest monetary aggregate that we consider is $M 1_{t}$, which is defined as currency plus demand deposits. In our model $M 1_{t}$ corresponds to $M_{t}+D_{t}$. The monetary base, $M 0_{t}$, is defined as currency in the hands of the non banking public plus total bank reserves. In our model, total bank reserves equal $A_{t}+X_{t}$. So, $M 0_{t}$ corresponds to $M_{t}+A_{t}+X_{t}$.

We now consider a variety of narrower monetary aggregates. Total bank reserves can be divided into required and excess reserves. In our model, these correspond to $\tau D_{t}$ and $E_{t}$, respectively. Total bank reserves can also be divided into borrowed and non borrowed reserves. To explain how we model these aggregates, we discuss our assumptions about monetary policy.

We suppose that the base evolves according to

$$
M 0_{t+1}=\left(1+x_{t}\right) M 0_{t}
$$

where the net growth rate of the base, $x_{t}$, consists of two components:

$$
x_{t}=x_{1 t}+x_{2 t}
$$

We assume that $x_{1 t}$ is purely exogenous, and evolves according to

$$
x_{1 t}=\left(1-\rho_{x}\right) x+\rho_{x} x_{1 t-1}+\epsilon_{x_{1} t}
$$


where $x$ is a positive scalar, $\left|\rho_{x}\right|<1$ and $\epsilon_{x_{1} t}$ is a mean zero, i.i.d. shock which has standard deviation $\sigma_{x_{1}}$, and is uncorrelated with all other shocks in the model.

The second component of $x_{t}, x_{2 t}$, is a function of the time $t$ innovations to the economy. In our stochastic sinulations, we allow only for two types of shocks, shocks to $x_{1 t}$, and shocks to the goods production function, $x_{f t}$. We proceed under the assumption:

$$
x_{2 t}=b_{1} \epsilon_{f t}+b_{2} \frac{\epsilon_{f t}}{1-\rho L}
$$

where $b_{1}$ and $b_{2}$ are scalars, $0<\rho<1$, and $L$ is the lag operator. We interpret $x_{2 t} M 0_{t}$ as the change in the stock of borrowed reserves. The change in non borrowed reserves equals the change in total reserves, less the change in borrowed reserves.

In (36), $b_{1}+b_{2}$ represents the impact effect of a technology shock on borrowed reserves. We assume that this effect is positive, so that the specification parsimoniously captures the notion emphasized by Goodfriend (1983) and others that the rationing rule used by the Fed at the discount window makes borrowed reserves an increasing function of shocks which raise short term interest rates. ${ }^{10}$ We also assume $b_{1}+b_{2} /(1-\rho)=0$. This corresponds to the assumption that any funds injected at the discount window are ultimately withdrawn. This captures the notion that loans made at the window are transitory in nature and must be repaid. 


\section{Quantitative Properties of the Model}

\subsection{Parameter Values}

In this section we analyze the quantitative properties of our model. We begin by discussing the model parameter values. The model has 25 parameters. The first $11,\left(\beta, \tau, \alpha, a_{f}, \mu_{z}\right.$, $\left.\delta, x, \Lambda_{1}, \Lambda_{2}, \nu_{0}, \nu_{1}\right)$, were set as follows. The discount rate was set to $4 \%$, at an annual rate. The reserve requirement, $\tau$, was set to 0.06 , the sample average of the ratio of required reserves to $M 1$ net of currency in the hands of the public. The production function parameter $\alpha$ was set to 0.36 , the value estimated by Christiano (1988), using National Income and Product Account data. The production parameter $a_{f}$ was normalized to 1 . The growth rate of productivity, $\mu_{z}$, was set so as to imply an unconditional annual growth rate of output of 1.6\%. This is the rate of growth of per capita output reported for the post-war period in Christiano and Eichenbaum (1992a). The depreciation rate, $\delta$, was set to imply an annual rate of depreciation of $8 \%$, based on the investment and capital stock data analyzed in Christiano and Eichenbaum (1992a). The growth rate in $M 0, x$, was set to $6.5 \%$, at an annual rate. This value was chosen so that the model would imply an annual inflation rate of $4.8 \%$ in steady state, the post-war annual average. The parameters, $\Lambda_{1}$ and $\Lambda_{2}$ were set to 1 and 0.3 , respectively, after experimenting with different values. The search technology parameter $\nu_{1}$ was chosen to equal 3.4. This implies that a $1 \%$ increase in time devoted to search leads to a $0.3 \%$ increase in the probability of finding employment. To obtain a value for $\nu_{0}$, we suppose that each unemployed person in the U.S. spends the same fraction of time, $l_{1 t}$, as an employed person spends working. In addition, we make the simplifying assumption 
that employed people do not engage in search. Under these assumptions, the mean of $l_{3 t}$ is the product of the mean of the unemployment rate $(U R)$ times the mean of the labor force participation rate $(L F P R)$ times the mean value of $l_{1 t}$ :

$$
l_{3}=U R \times L F P R \times l_{1} .
$$

Based on post war average data, $U R=.066, L F P R=.6, l_{1}=0.38$, so that $l_{3}=0.015$.

The next 7 parameters which we consider are $\left(N, J, \theta, \gamma, a_{b}, \zeta, \psi\right)$. Here, $1 / N$ denotes the model period, expressed as a fraction of a year. These parameters were set so that, given the parameters just discussed, the steady state properties of the model satisfy the following 7 conditions:

$$
n l_{1}=0.23, r_{b}=0.083, r_{a}=0.069, \frac{D_{t}}{M_{t}}=3.18, \frac{E_{t}}{P_{t} C_{t}}=0.0004, \frac{D_{t}}{P_{t} C_{t}}=0.19, l_{2}=.004 .
$$

The value to which we set $n l_{1}$ is the sample average of per capita hours worked, as measured by Hansen (1985), scaled by households' time endowment. We assume this equals 15 hours per day. To define $r_{b}$, recall that $r_{f t}$ is the interest rate paid on bank loans, net of the time $t$ interest rate on checking accounts. The interest rate, $r_{f t}$, is the lending rate, gross of interest on checking accounts:

$$
r_{b t}=r_{f t}+r_{a t}
$$

Then, $r_{b}$ is the nonstochastic steady-state value of $r_{b t}$. The values to which we set $r_{b}$ and $r_{a}$ are the post-war sample averages of the prime lending rate and the federal funds rate, respectively (CITIBASE mnemonics FYPR and FYFF). To motivate identifying $r_{a t}$ with the federal funds rate, note that in the model $r_{a t}$ is also the interest rate on inter bank loans. The variables $M_{t}, E_{t}$, and $D_{t}$ were measured using data on currency held by the non 
banking public, excess reserves held by the banking system and deposits held in US banks, respectively (CITIBASE mnemonics FMSCU, FMRRA - FMRQA and FM1-FMSCU). The variables $P_{t}$ and $C_{t}$ are the GDP deflator and the value of consumption used in Christiano and Eichenbaum (1992a), respectively. The value of $l_{2}$ corresponds to 25 minutes per week, assuming a 15 hour per day time endowment. This value was selected a priori. Quantities with a time dimension are expressed in annual rates. Prior to solving and simulating the nodel, parameters with a time dimension were converted to units corresponding to the time period of the nodel.

The last 7 parameters characterize the stochastic properties of the shocks. The parameters $\rho_{f}$ and $\rho_{x}$ were set to 0.5 and 0.1 . We set $\sigma_{f}$ and $\sigma_{x}$ to 0.0097 and 0.0038 . Finally, we set the borrowed reserves parameters $b_{1}, b_{2}$, and $\rho$ to $3,-2.1$ and 0.3 , respectively. These parameters were chosen by an informal search procedure. The objective was to identify a parameterization of the model which captures the facts emphasized in section 2 and which is consistent with the observed variability in aggregate output. All reported second moment properties of the model pertain to the model period.

Table 1 summarizes the model parameter values. The estimated value of $\mathrm{N}$ implies that the length of the model period is roughly one-half of the (quarterly) data sampling interval. The non stochastic steady state of the model is summarized in Table 2. A number of features are worth noting here. First, the fraction of the aggregate capital stock and aggregate employment used in the banking sector are very small. This reflects the large value of $a_{b}$ that emerges from our calibration exercise.

Second, the nonstochastic steady state values of $C / Y$ and $K / Y$ equal 0.76 and 2.44, respectively. These are similar to the corresponding sample averages reported in the data 
used by Christiano and Eichenbaum (1992a). Third, the model implies that the fraction of the population who are employed equals $n=0.48$. Over the period 1948-1993, the sample average of the ratio of employed civilian workers to the civilian non-institutional population over the age of 16 is 0.59 . The ratio of total employment (including the military) to the total population is 0.415 . Given the ambiguity regarding which measure of the population is appropriate for our model, a value of $n=.48$ seems reasonable. Finally, according to the model, $l_{2}$ is equal to 0.004 .

Table 3 summarizes the balance sheet of the banking sector in non stochastic steady state. The main things to notice are that (i) consistent with the data, average excess reserves are very small, and (ii) roughly $75 \%$ of the bank's assets consist of working capital loans. The remaining assets consist of reserves and loans to fund investment. All of the banks' liabilities consist of demand deposits.

\subsection{Impulse Response Functions}

In this subsection we discuss the dynamic response of our model economy to a unit shock in $\epsilon_{x t}$ and $\epsilon_{f t}$. To compute these responses, we use the approximate log linear solution procedure discussed in Christiano and Valdivia (1994).

\section{A Shock to the Growth Rate of Money}

The three panels in Table 4 report the contemporaneous and lagged responses of several variables to a one percentage point innovation in the growth rate of the monetary base. Consider first the response of short term interest rates (Panel A). In the impact period of the shock, $r_{b t}$ and $r_{a t}$ fall by roughly 43 and 40 basis points, respectively, after which they converge to their unchanged non stochastic steady state path from below. 
The limited participation mechanism underlying the contemporaneous decline in interest rates assumes that households cannot increase their holdings of currency in response to a positive money shock. As a result, the innovation in the monetary base shows up dollarfor-dollar as a rise in the reserves of banks. This generates a liquidity effect, which exerts downward pressure on the interest rate, as banks lend out their extra reserves. We have assumed that the growth rate of the base is positively autocorrelated, so that a money shock also generates upward pressure on interest rates, via an expected inflation effect. Which effect dominates is a quantitative issue. In our model, the liquidity effect dominates.

The result that a monetary policy shock induces a persistent decline in interest rates, reflects the assumption that it is costly for households to increase their currency holdings. Because of these costs, currency holdings rise to their new steady state path only slowly from below. Throughout the transition period, a relatively high proportion of the base consists of reserves in the banking system. And as long as this is the case, interest rates remain relatively low.

A natural question is: how large are our assumed adjustment costs? Based on the following calculations, we conclude that the costs are very small. We reach this conclusion by computing agents' portfolio decisions when they (sub optimally) ignore adjustment costs and by measuring the amount of time, $l_{4}$, that the resulting rapid portfolio adjustments entail. The resulting sequence of time spent on adjusting portfolios, $l_{4 t}$, is a measure of the adjustment costs that the optimal decision rules avoid. We find that the sequence of $l_{4}$ 's computed in this way amount to less than one minute a week over the first six months after a one percentage point shock to money growth. Evidently, only very small adjustment costs in $M_{t} / M_{t-1}$ are needed to generate persistent liquidity effects. Adjustment costs of such 
small magnitude seem very plausible.

Next, we consider the response of different monetary aggregates to a positive monetary policy shock. According to Table 4, such a shock leads to sizable, persistent increases in bank reserves, $M 0, M 1$ and excess reserves. The increase in $M 1$ reflects a rise in bank loans, which generates a rise in demand deposits. Excess reserves rise because the opportunity cost of holding them $\left(r_{b t}\right)$ has declined.

A key feature of our results is the differential sensitivity of bank reserves, $M 0$ and $M 1$ to the monetary policy shock. ${ }^{11}$ Initially, $M 0$ rises by $0.99 \%$, after which it converges to its new steady state path, which is 1.10 percent above the unshocked path. In contrast, reserves initially rise by more than $6 \%$. This sensitivity reflects our assumption that households do not change their currency holdings immediately after a shock to monetary policy. This implies that all of the initial increase in the $M 0$ takes the form of an increase in bank reserves.

According to Table 4, M1 is also more sensitive than $M 0$ to a monetary policy shock Initially $M 1$ rises by about $2.2 \%$ and then slowly converges to its steady state path from above. The sensitivity of $M 1$ reflects a sharp expansion in the 'endogenous' components of $M 1$ in response to the policy shock. Specifically, the decline in interest rates following the policy shock is associated with a rise in bank loans for working capital and investment purchases. So, for different reasons, reserves and $M 1$ rise more sharply than $M 0$ following a positive monetary policy shock.

Next, we consider the response of various real quantities to a positive monetary policy shock. Table 4 reveals that such a shock leads to a rise in consumption, investment, goods output, the total number of people employed and hours worked per employed person $\left(l_{1 t}\right)$. The intuition for the rise in employment is similar to that underlying the analog result in 
simple cash in advance limited participation models. Firms must obtain loans from banks to pay labor. By reducing the marginal cost of labor, the fall in interest rates after a positive policy shock leads to a rise in the demand for labor. While there are other potentially offsetting effects, the demand for labor effect is the dominant one in terms of explaining the movement in aggregate employment.

Notice that the number of people employed in the banking sector, $n_{b}$, declines even though $l_{1 t}$ rises. The intuition for the decline in $n_{b}$ is as follows. After the policy shock, goods output rises, drawing resources - both capital and people - from the banking sector into the goods producing sector. A simple calculation shows that the rise in hours worked in the banking sector does not compensate for the fall in $k_{b t}$ and $n_{b t}$. However the rise in excess reserves allows total output of the banking sector to expand.

Table 4 also reveals an important shortcoming of our model: the inflation rate rises sharply in the impact period of the shock. Thereafter, inflation falls and converges to its nonstochastic steady state level from below. This response pattern is inconsistent with empirical estimates reported in the literature. For example, an implication of results in Christiano, Eichenbaum and Evans (1995) is that, after a positive monetary policy shock, the inflation rate does not respond for about a year, after which it rises.

\section{A Technology Shock to the Goods Producing Sector}

Tables 5 and 6 report the contemporaneous and lagged responses of several variables to a one percent positive shock to the technology for producing goods. Table 5 assumes there is no monetary accommodation via the discount window (i.e., $b_{1}=b_{2}=0$ ), while Table 6 reports results for the case with accommodation, with parameter values reported in Table 1. 
According to Table 6, a shock to $x_{f t}$ leads to a persistent rise in employment, average hours worked, output, consumption and investment. The intuition for these effects is very similar to that underlying the effects of a technology shock in standard Real Business Cycle models.

On the monetary side of the economy, the shock to $x_{f t}$ stimulates a rise in the demand for loans by firms. Banks supply the increased loans, which show up as an increase in $M 1$, by hiring more factors of production and, in the impact period of the shock, running down excess reserves. In the impact period of the shock, the only way the banking system can increase loans is by reducing excess reserves. This reflects the no-accommodation assumption on the discount window and the assumption that households don't change their currency holdings in the impact period of the monetary policy shock. After a one period delay, reserves flow into the banking system as households respond to higher interest rates by decreasing their currency holdings, and increasing deposits, $A$. Banks use these reserves to increase loans and replenish excess reserves. The net result is that technology shocks induce positive comovements between reserves, $M 1$ and interest rates.

Notice also that, according to the model, both technology and monetary policy shocks, induce positive comovements between output and various monetary aggregates. So, the model captures the endogeneity of broad monetary aggregates to non-policy shocks emphasized by Friedman and Schwartz (1963), and King and Plosser (1984), among others. At the same time, because of the assumption that households don't change their currency holdings in the impact period of the shock, $M 1$ responds more sharply to output, at least contemporaneously, than does reserves. This differential sensitivity is, in principle, capable of rationalizing the fact, documented in section 2 , that $M 1$ is more highly correlated (at 
least contemporaneously) with output than is non borrowed reserves.

In the previous experiment, a shock to technology does not change the monetary base. Analyzing this case is useful for building intuition about the effects of a technology shock. It also shows why it is important to have a feedback component to monetary policy. Without this, we could not account for the observed positive correlations between the interest rate and the monetary base and the interest rate and borrowed reserves. With accommodation, the model has a source of positive comovements between borrowed reserves, the base with interest rates. That this is the case is evident from Table 6. Also notice from that table that, with $b_{2}<0$, the base quickly reverts to its unperturbed steady state path, as the borrowed reserves injected at the time of the technology shock are withdrawn.

For the most part, the responses reported in Table 6 are just a simple combination of the responses in Tables 4 and 5. Still, there are five features of Table 6 that we wish to emphasize. First, the response of non borrowed reserves is now sharply different from that of total reserves. For example, in the impact period of the shock non borrowed reserves remain unchanged, while total reserves are up 5.4 percent. All of this rise in total reserves reflects the increase in borrowed reserves. Second, excess reserves no longer fall - instead, they rise sharply - in the period of the technology shock. Third, the base and $M 1$ rise by more when there is monetary accommodation. Fourth, the borrowed reserves policy has the effect of reducing the equilibrium interest rate response to a technology shock. In this sense, the discount window acts to smooth interest rates. Fifth, the borrowed reserves policy has the effect of increasing the output response of a technology shock. Christiano and Eichenbaum (1994) analyze the last two phenomena in a cash-in-advance, limited participation economy. 


\subsection{Second Moment Properties}

In this subsection we discuss the second moment properties of the model. We begin by considering the implications of the model for real variables. We then turn to the monetary properties of the model.

\section{Real Variables}

Tables $7 \mathrm{a}$ and $7 \mathrm{~b}$ report selected second moments of real variables for the U.S. data and for our model, respectively. The key property to note is that our model shares most of the strengths and weaknesses of standard real business cycle models. For example, it accurately predicts that consumption is smooth relative to income, and that investment is volatile. Like most real business cycle models, it fairs less well in accounting for aspects of labor market fluctuations. For example, it under predicts the volatility of employment and hours worked per employed person and over predicts the correlation of productivity with output. A success of the model is that it accurately predicts that hours per person is about half as volatile as employment. Still the main finding here is that the real variables in our model economy behave very much as they do in standard real business cycle models. In fact, when we shut down the stochastic components of the monetary base, we found that the second moment properties reported in Table $7 \mathrm{~b}$ were virtually unaffected.

\section{Monetary Variables}

We now turn to the implications of our model for monetary variables. We first consider the sign switch observations. We then turn to the money-output and interest rate-output correlations. 
Panel A of Table 8 presents estimates of the correlation between the federal funds rate and various monetary aggregates. The analog correlations for the baseline model are presented in Panel B. In comparing the numbers in these tables, it is useful to bear in mind that the model time period is one-half the data sampling period.

Four key results are worth noting. First, the model correctly accounts for the fact that $r_{a}$ displays a weak contemporaneous correlation with M1 and the base and a strong negative contemporaneous correlation with non borrowed reserves. Moreover, the model does quite well, from a quantitative point of view, at matching the contemporaneous correlations between these variables. Second, the model reproduces a basic feature of the correlation functions between $r_{a}$ and the base, and between $r_{a}$ and $M 1$. Specifically, the model is consistent with the fact that $r_{a}$ is positively correlated with lagged values of the base and $M 1$, but negatively correlated with their future values. Third, the model captures the symmetric nature of the empirical correlation function between $r_{a}$ and non borrowed reserves, with $r_{a}$ being negatively correlated with future and past non borrowed reserves. Fourth, at a quantitative level, the model is less successful at reproducing the extent to which $r_{a}$ is negatively correlated with future non borrowed reserves and $M 1$.

To understand this last shortcoming recall that, in our model, technology shocks contribute to a positive correlation between $r_{\boldsymbol{a}}$ and future monetary aggregates, while monetary shocks contribute to a negative correlation. The first effect arises because a positive technology shock leads to a contemporaneous rise in the interest rate and to a persistent rise in output, as well as non borrowed reserves and $M 1$. The second effect arises because a positive monetary policy shock leads to a fall in the current interest rate and a persistent rise in output, as well as non borrowed reserves and $M 1$. The shortcoming of the model reflects 
the relative importance of the role of technology shocks. This suggests two remedies to the problem: make the dynamic impact of technology shocks on output less important and/or make the dynamic impact of a monetary policy shock on output more important. ${ }^{12}$ The model does better at accounting for the correlation between $r_{a}$ and future values of the base because technology shocks do not have an important dynamic effect on $M 0$. This reflects our assumptions about discount window policy, according to which reserves that are injected in the impact period of a shock are withdrawn thereafter.

To help convey intuition about the features of our model which allow it to account for the sign switch, Panels $\mathrm{C}$ and D of Table 8 report results for two variants of the model. Panel C pertains to a variant of the baseline model in which there are no borrowed reserves, i.e. $b_{1}=b_{2}=0$. Panel $\mathrm{D}$ pertains to a variant of the baseline model in which (i) households can change their currency holdings in the impact period of shocks to the economy, and (ii) there are no adjustment costs associated with changing currency holdings between periods $\left(\Lambda_{1}=\Lambda_{2}=0\right.$.) Panel $\mathrm{C}$ indicates that setting the parameters $b_{1}$ and $b_{2}$ to zero lowers the correlation between $r_{a}$ and the monetary base, reflecting the fact that, in the benchmark model, the only source of endogeneity in the base is borrowed reserves. Absent this source, the base comoves negatively with $r_{a}$.

Comparing the results in Panels $\mathrm{B}$ and $\mathrm{D}$ allows us to evaluate the impact of the assumption that households cannot adjust currency holdings in the impact period of shocks. The key thing to note is that absent this assumption $r_{a}$ displays a positive contemporaneous correlation with all of the monetary aggregates. This is because, absent a liquidity effect, exogenous shocks to the growth rate of the base drive interest rates up, not down. So, in our analysis, the assumed contemporaneous rigidity in household currency holdings is a 
necessary condition for accounting for the sign switch.

We now turn to an analysis of the correlation between the interest rate and output. First, notice that the model does well at matching the contemporaneous correlation between $r_{a}$ and output. At a qualitative level, it reproduces the fact that the correlation between $r_{a}$ and past output is much greater than the correlation between $r_{a}$ and future output. However, it does not reproduce the strong negative correlation between $r_{a}$ and future output that is observed in the data. This reflects the relative importance of technology shocks in our model.

Finally, we turn to table 9 , which presents the correlations between the various monetary aggregates in our model and output. There are three key features to note. First, the model correctly accounts for the fact that the monetary base and $M 1$ are positively correlated with current and future output. Second, the model accounts for the fact that the base and $M 1$ are more positively correlated with current output than non borrowed reserves. Third, the model does not account for the fact that non borrowed reserves are negatively correlated with current and past levels of output. This may reflect omitted shocks or a misspecified monetary policy rule.

\section{Summary and Conclusion}

In this paper we have developed a simple quantitative business cycle model that allows for multiple monetary aggregates. We used a version of the model to discuss two important features of post-war U.S. time series data: (i) broad monetary aggregates covary positively with output and (ii) the base and M1 are positively correlated, while non borrowed reserves are negatively correlated with current and future interest rates. reserves. 
The version of the model we work with accounts for (i) as reflecting the response of money to technology shocks and the impact on output and broad monetary aggregates of exogenous shocks to monetary policy. As for (ii), our model accounts for the negative correlation between non borrowed reserves and the interest rate as reflecting the relative importance of exogenous money supply shocks in non borrowed reserves and the importance of liquidity effects in the monetary transmission mechanism.

Our model accounts for the other feature of (ii) - the positive correlation between broad monetary aggregates and the interest rate - as reflecting two sources of endogeneity in these aggregates. The first is the Federal Reserve's discount window, which acts to increase the borrowed component of bank reserves when the interest rate is high. Although this source of endogeneity affects all the monetary aggregates, its impact on non borrowed reserves is relatively small. This is because this impact must operate indirectly via a change in the currency holdings of the nonbanking public. The frictions in our model imply that these change only slowly. By contrast, for example, the impact of an increase in borrowed reserves on the monetary base is immediate and automatic. The second source of endogeneity, whose principal effect is on $M 1$, is the banking system itself. It has an incentive to increase loans when interest rates are high. Since bank loans give rise to the creation of bank deposits, this produces upward pressure on $M 1$ when interest rates are high.

The paper also documented some important shortcomings of our model. One set of shortcomings reflects the weak magnification and propagation of monetary shocks. This manifests itself in three model failures. First, the model fails to reproduce the empirical observation that broader monetary aggregates are more strongly correlated with future rather than past output. Second, the model fails to reproduce the fact that the interest rate is 
negatively correlated with future GNP (see Christiano and Eichenbaum (1995)). Third, the model greatly overstates the response of the price level to a monetary injection.

The weak effects of monetary shocks in the model are all the more notable because our workweek of capital formulation of the production technology was designed in part with the objective of enhancing the output effect of a monetary shock. As compared with the standard production technology, the fact that shift lengths can be varied offers firms extra flexibility for increasing output after an interest rate decrease. A feature of this option is that, by increasing the services of both capital and labor simultaneously, increasing output by increasing shift length does not reduce the marginal productivity of factors of production. In fact, if interest rates and marginal productivities were the only considerations, an interest rate decrease would result in an infinite increase in output in the workweek model (see (7).) In practice, however, this model feature does not substantially enhance the output effect of a money shock. This is because equilibrium wage payments, as a function of shift length, rise sharply in our model.

A second shortcoming of the model is that it predicts a positive correlation between non borrowed reserves and output, while in the data this correlation is negative. Presumably, the empirical correlation reflects a policy of 'leaning against the wind' by the FOMC. This is entirely missing from our model, which assumes the actions of the FOMC are exogenous. An important task is to overcome this shortcoming by endogenizing the actions of the FOMC. It would be interesting to see if this can be done in a version of the model which also corrects for the lack of magnification and propagation of exogenous monetary policy shocks. 


\section{Footnotes}

1. Movements in the non borrowed component of the monetary base (i.e., currency plus non borrowed reserves) are implemented by the actions of the Federal Reserve Open Market committee. The movements in reserves are 'non borrowed ' because they are effected by a swap of ownership over assets: reserves at the central bank in exchange for interest bearing assets, typically U.S. government debt. Movements in borrowed reserves occur with variations in the amount of loans made by at the Federal Reserve discount window. Our model of the actions of these two organs of the Fed abstracts from the details of how they implement policy, and simply assumes that they effect changes in reserves by a 'helicopter drop'.

2. This is consistent with the empirical evidence that the short run elasticity of the demand for currency is very low (see for example the discussion in Lucas (1990)).

3. The notion that an expansionary open market operation leads to a disproportionate rise in bank reserves is implicit in standard discussions of the effects of open market operations on the market for bank reserves and the federal funds rate. See for example Goodfriend (1983).

4. In arguing that expanionary exogenous monetary policy shocks drive interest rates down, Christiano, Eichenbaum and Evans (1995) and Bernanke and Minhov (1995) explicitly allow for this possibility.

5. Christiano and Eichenbaum (1992b) document the robustness of these conclusions to different sample periods and different transformations of the data.

6. See Christiano, Eichenbaum and Evans (1995) and the references therein.

7. This technology is the same as that used in Kydland and Prescott (1988) and Horn- 
stein and Prescott (1993), among others. See Burnside, Eichenbaum and Rebelo (1995) for evidence regarding the empirical plausibility of this specification.

8. As in Lucas (1993), we ignore the costs involved in managing banks' assets.

9. It can be show that the capital - labor ratio and the workweek of labor in the banking and goods producing sector are the same.

10. See also Bernanke and Mihov (1995) and the references therein.

11. Recall that, absent monetary accommodation to the technology shock and given the limited participation assumption, the response of non borrowed and total reserves to a monetary policy shock is identical.

12. There is a third option: increase the impact effect of a monetary policy shock on the interest rate and/or decrease the impact effect of a technology shock on the interest rate. We are som ${ }^{\circ}$ hat skeptical of this solution because the contemporaneous interest rate effect of a technology shock is already quite low in the model, while the contemporaneous interest rate effect of a monetary policy shock is high. 


\section{$7 \quad$ References}

Bernanke. Ben and Ilian Mihov. 'Measuring Monetary Policy'. Unpublished paper, (1995).

Burnside, Craig, Eichenbaum, Martin and Rebelo, Sergio. 'Capacity Utilization and Returns to Scale'. Forthcoming, NBER Macro Annual, 1995.

Christiano, Lawrence J. 'Why Does Inventory Investment Fluctuate So Much?'. Journal of Monetary Economics 21 (March/May 1988), $247-280$.

Christiano, Lawrence J. 'Comment on Pagan and Robertson'. Forthcoming, Federal Reserve Bank of St. Louis Review, 1995.

Christiano, Lawrence J. and Martin Eichenbaum. 'Current Real Business Cycle Theories and Aggregate Labor Market Fluctuations'. American Economic Review, 82, (June, 1992a), 430-450.

Christiano, Lawrence J. and Martin Eichenbaum, 'Identification and the Liquidity Effects of a Monetary Shock'. In Political Economy, Growth and Business Cycles, edited by Alex Cukierman, L. Zvi Hercowitz, and Leonardo Leiderman: MIT Press, 1992b.

Christiano, Lawrence J. and Martin Eichenbaum. 'Liquidity Effects and the Monetary Transmission Mechanism'. American Economic Review 82 (May, 1992c) 346-353.

Christiano, Lawrence J. and Martin Eichenbaum. 'Interest Rate Smoothing in a Business Cycle Smoothing Model'. Unpublished paper, 1994. 
Christiano, Lawrence J. and Martin Eichenbaum. 'Liquidity Effects, Monetary Policy and the Business Cycle'. Journal of Money, Credit and Banking (November, Part I, 1995).

Christiano, Lawrence J., Martin Eichenbaum, and Charles Evans. 'What Happens After a Monetary Policy Shock? Evidence from the Flow of Funds'. Forthcoming, Review of Economics and Statistics (1995).

Christiano, Lawrence J. and Victor Valdivia. 'Notes on Solving Models Using a Linearization Method'. Unpublished paper, 1994.

Friedman, Milton and Anna Schwartz. A Monetary History of the United States, 1867-1960, Princeton University Press, 1963.

Fuerst, Timothy (1992). 'Liquidity, Loanable Funds, and Real Activity'. Journal of Monetary Economics 29, (February, 1992), 3-24.

Goodfriend, Marvin. 'Discount Borrowing, Monetary Policy and Post-October 1979 Federal Reserve Operating Procedures'. Journal of Monetary Economics 12 (September, 1983), $345-356$.

Hansen, Gary. D. 'Indivisible Labor and the Business Cycle'. Journal of Monetary Economics 16 (November, 1985), 309-328.

Hodrick, Robert J. and Edward C. Prescott. 'Post-War Business Cycles: An Empirical Investigation'. Unpublished paper, 1980.

Hornstein, Andreas and Edward C. Prescott. 'The Firm and the Plant in General Equilibrium Theory'. In General Equilibrium, Growth, and Trade II, The Legacy of Li- 
onel McKenzie, edited by Robert Becker, Michele Boldrin, Ronald Jones, and William Thomson: Academic Press, 1993.

King, Robert G. and Charles I. Plosser. 'Money, Credit and Prices in a Real Business Cycle Model,' American Economic Review 74 (June, 1984), 363-380.

Kydland, Finn and Edward C. Prescott. "The Workweek of Capital and Its Cyclical Implications'. The Journal of Monetary Economic 21 (March/May, 1988), 343-360.

Lucas, Robert E., Jr. 'Liquidity and Interest Rates'. Journal of Economic Theory 50 (April, 1990), 237-264.

Lucas, Robert E. Jr. 'On the Welfare Costs of Inflation'. Unpublished Paper, 1993.

McCallum, Bennett T, and Marvin S. Goodfriend. 'Demand for Money: Theoretical Studies'. In The New Palgrave: A Dictionary of Economics, edited by John Eatwell, Murray Milgate, and Peter Newman: Stockton Press, 1987.

Mishkin, Frederic S. The Economics of Money, Banking, and Financial Markets. Harper Collins, 1992. 
Table 1: Model parameters*

Period of model (fraction of year): 0.11

* Parameters with a time dimension expressed at an annual rate

Table 2: Some properties of non stochastic steady state*

\begin{tabular}{llllllllll}
\hline $\mathrm{K}_{b} / \mathrm{K}$ & .001 & $\mathrm{l}_{1}$ & .48 & $\pi$ & $4.8 \%$ & $\mathrm{D} / \mathrm{M}$ & 3.18 & $\mathrm{PY} / \mathrm{M}$ & 21.6 \\
$\mathrm{~N}_{b} / \mathrm{N}$ & .001 & $\mathrm{l}_{2}$ & .004 & $\mathrm{r}_{f}$ & $8.3 \%$ & $\mathrm{E} /(\mathrm{PC})$ & .0004 & $\mathrm{PY} / \mathrm{M} 0$ & 18.0 \\
$\mathrm{~K} / \mathrm{Y}$ & 2.44 & $\mathrm{l}_{3}$ & .015 & $\mathrm{r}_{a}$ & $6.9 \%$ & $\mathrm{D} /(\mathrm{PC})$ & .194 & $\mathrm{PY} / \mathrm{M} 1$ & 5.2 \\
$\mathrm{C} / \mathrm{Y}$ & .76 & $\mathrm{n}$ & .48 & $\mathrm{r}_{k}$ & $14 \%$ & M1/M & 4.31 & & \\
& & $\mathrm{nl}_{1}$ & .23 & & & M1/M0 & 3.36 & & \\
\hline \multicolumn{7}{c}{ * Variables }
\end{tabular}

* Variables with a time dimension expressed at an anmual rate

Table 3: Banking sector balance sheet (non stochastic steady state)*

\begin{tabular}{lc|ll}
\hline Assets & & Liabilities & \\
\hline Reserves & .062 & Demand deposits & 1.0 \\
Required & .060 & & \\
Excess & .002 & & \\
Working capital & .755 & & \\
$\quad$ Wage loans & .483 & & \\
Capital rental loans & .272 & & \\
Investment loans & .182 & & \\
\hline
\end{tabular}

* Numbers expressed as a fraction of total bank assets 
Table 4: Response to a money supply shock* Panel A: Interest rates, inflation and reserves

\begin{tabular}{rrrrrrr}
\hline & $r_{a}$ & $r_{b}$ & $\pi$ & NBR & ER & TR \\
\hline 0 & -0.40 & -0.43 & 1.76 & 6.01 & 93.57 & 6.01 \\
1 & -0.37 & -0.39 & -0.32 & 3.59 & 48.55 & 3.59 \\
2 & -0.17 & -0.18 & -0.18 & 2.25 & 23.03 & 2.25 \\
3 & -0.08 & -0.08 & -0.08 & 1.62 & 10.97 & 1.62 \\
4 & -0.04 & -0.04 & -0.04 & 1.34 & 5.46 & 1.34 \\
5 & -0.02 & -0.02 & -0.02 & 1.21 & 2.95 & 1.21 \\
6 & -0.01 & -0.01 & -0.01 & 1.15 & 1.82 & 1.15 \\
7 & -0.00 & -0.00 & -0.00 & 1.12 & 1.31 & 1.12 \\
8 & -0.00 & -0.00 & -0.00 & 1.11 & 1.08 & 1.11 \\
9 & -0.00 & -0.00 & -0.00 & 1.10 & 0.98 & 1.10 \\
\hline
\end{tabular}

Panel B: Monetary aggregates

\begin{tabular}{rrrrrr}
\hline & $\mathrm{M}$ & $\mathrm{A}$ & Base & M1 & Loans \\
\hline 0 & 0 & 0 & 0.99 & 2.20 & 2.68 \\
1 & 0.60 & 3.07 & 1.09 & 1.65 & 1.87 \\
2 & 0.87 & 2.24 & 1.10 & 1.36 & 1.46 \\
3 & 1.00 & 1.64 & 1.10 & 1.22 & 1.27 \\
4 & 1.06 & 1.35 & 1.10 & 1.16 & 1.18 \\
5 & 1.08 & 1.21 & 1.10 & 1.13 & 1.14 \\
6 & 1.09 & 1.15 & 1.10 & 1.12 & 1.12 \\
7 & 1.10 & 1.12 & 1.10 & 1.11 & 1.11 \\
8 & 1.10 & 1.11 & 1.10 & 1.11 & 1.11 \\
9 & 1.10 & 1.10 & 1.10 & 1.11 & 1.11 \\
\hline
\end{tabular}

Panel C: Real quantities

\begin{tabular}{rrrrrrr}
\hline & $\mathrm{C}$ & $\mathrm{I}$ & $\mathrm{Y}$ & $n_{f}$ & $n_{b}$ & $l_{1}$ \\
\hline 0 & 0.14 & 1.07 & 0.37 & 0.31 & -0.38 & 0.17 \\
1 & 0.00 & 0.13 & 0.03 & 0.03 & -0.41 & 0.01 \\
2 & 0.01 & 0.06 & 0.02 & 0.01 & -0.19 & 0.01 \\
3 & 0.01 & 0.02 & 0.01 & 0.00 & -0.09 & 0.00 \\
4 & 0.01 & 0.01 & 0.01 & 0.00 & -0.04 & 0.00 \\
5 & 0.01 & -0.00 & 0.00 & -0.00 & -0.02 & -0.00 \\
6 & 0.01 & -0.00 & 0.00 & -0.00 & -0.01 & -0.00 \\
7 & 0.01 & -0.01 & 0.00 & -0.00 & -0.01 & -0.00 \\
8 & 0.01 & -0.01 & 0.00 & -0.00 & -0.00 & -0.00 \\
9 & 0.01 & -0.01 & 0.00 & -0.00 & -0.00 & -0.00 \\
\hline
\end{tabular}

*Response to a one percentage point innovation in $x_{1}$. Entries for $r_{a}, r_{b}$ and $\pi$ report the percentage point deviation of these variables from their unshocked steady state path. All other entries report percent deviations from their unshocked steady state paths. 
Table 5: Response to a technology shock without monetary accommodation* Panel A: Interest rates, inflation and reserves

\begin{tabular}{rrrrrrr}
\hline & $r_{a}$ & $r_{b}$ & $\pi$ & NBR & ER & TR \\
\hline 0 & 0.54 & 0.58 & -0.49 & 0 & -24.49 & 0 \\
1 & 0.31 & 0.33 & 0.38 & 1.21 & 10.21 & 1.21 \\
2 & 0.07 & 0.08 & 0.14 & 1.14 & 14.84 & 1.14 \\
3 & -0.00 & -0.00 & 0.03 & 0.80 & 11.31 & 0.80 \\
4 & -0.02 & -0.02 & -0.00 & 0.50 & 6.90 & 0.50 \\
5 & -0.02 & -0.02 & -0.01 & 0.28 & 3.51 & 0.28 \\
6 & -0.01 & -0.01 & -0.01 & 0.15 & 1.29 & 0.15 \\
7 & -0.01 & -0.01 & -0.01 & 0.06 & -0.06 & 0.06 \\
8 & -0.00 & -0.00 & -0.00 & 0.02 & -0.83 & 0.02 \\
9 & -0.00 & -0.00 & -0.00 & -0.01 & -1.25 & -0.01 \\
\hline
\end{tabular}

Panel B: Monetary aggregates

\begin{tabular}{rrrrrr}
\hline & M & A & Base & M1 & Loans \\
\hline 0 & 0 & 0 & 0 & 0.67 & 0.93 \\
1 & -0.24 & 1.26 & 0 & 0.62 & 0.86 \\
2 & -0.23 & 1.19 & 0 & 0.44 & 0.62 \\
3 & -0.16 & 0.84 & 0 & 0.29 & 0.40 \\
4 & -0.10 & 0.52 & 0 & 0.18 & 0.25 \\
5 & -0.06 & 0.29 & 0 & 0.11 & 0.16 \\
6 & -0.03 & 0.15 & 0 & 0.07 & 0.10 \\
7 & -0.01 & 0.07 & 0 & 0.05 & 0.07 \\
8 & -0.00 & 0.02 & 0 & 0.04 & 0.05 \\
9 & 0.00 & -0.01 & 0 & 0.03 & 0.04 \\
\hline
\end{tabular}

Panel C: Real quantities

\begin{tabular}{rrrrrrr}
\hline & $\mathrm{C}$ & $\mathrm{I}$ & $\mathrm{Y}$ & $n_{f}$ & $n_{b}$ & $l_{1}$ \\
\hline 0 & 0.20 & 4.78 & 1.31 & 0.26 & 2.22 & 0.14 \\
1 & 0.22 & 2.98 & 0.89 & 0.31 & 1.18 & 0.17 \\
2 & 0.14 & 1.49 & 0.47 & 0.15 & 0.49 & 0.09 \\
3 & 0.10 & 0.73 & 0.25 & 0.07 & 0.20 & 0.04 \\
4 & 0.07 & 0.35 & 0.14 & 0.03 & 0.07 & 0.02 \\
5 & 0.06 & 0.15 & 0.08 & 0.01 & 0.02 & 0.01 \\
6 & 0.06 & 0.05 & 0.05 & -0.00 & 0.00 & -0.00 \\
7 & 0.05 & -0.00 & 0.04 & -0.01 & -0.01 & -0.00 \\
8 & 0.05 & -0.03 & 0.03 & -0.01 & -0.01 & -0.01 \\
9 & 0.05 & -0.04 & 0.03 & -0.01 & -0.01 & -0.01 \\
\hline
\end{tabular}

*Response to a one percentage point innovation in $x_{f}, b_{1}=b_{2}=0$. Entries for $r_{a}, r_{b}$ and $\pi$ report the percentage point deviation of these variables from their unshocked steady state path. All other entries report percent deviations from their unshocked steady state paths. 
Table 6: Response to a technology shock with monetary accommodation* Panel A: Interest rates, inflation and reserves

\begin{tabular}{rrrrrrr}
\hline & $r_{a}$ & $r_{b}$ & $\pi$ & NBR & ER & TR \\
\hline 0 & 0.05 & 0.05 & -0.37 & 0 & 89.65 & 5.41 \\
1 & 0.13 & 0.14 & 0.24 & 0.64 & 32.83 & 2.23 \\
2 & 0.06 & 0.06 & 0.12 & 0.73 & 16.21 & 1.17 \\
3 & 0.01 & 0.01 & 0.04 & 0.59 & 9.18 & 0.69 \\
4 & -0.00 & -0.00 & 0.01 & 0.41 & 5.02 & 0.40 \\
5 & -0.01 & -0.01 & -0.00 & 0.26 & 2.29 & 0.22 \\
6 & -0.01 & -0.01 & -0.00 & 0.16 & 0.54 & 0.11 \\
7 & -0.00 & -0.00 & -0.00 & 0.10 & -0.54 & 0.05 \\
8 & -0.00 & -0.00 & -0.00 & 0.06 & -1.18 & 0.01 \\
9 & -0.00 & -0.00 & -0.00 & 0.04 & -1.53 & -0.01 \\
\hline
\end{tabular}

Panel B: Monetary aggregates

\begin{tabular}{rrrrrr}
\hline & $\mathrm{M}$ & $\mathrm{A}$ & Base & M1 & Loans \\
\hline 0 & 0 & 0 & 0.89 & 1.84 & 2.20 \\
1 & -0.12 & 6.25 & 0.27 & 0.84 & 1.06 \\
2 & -0.14 & 2.40 & 0.08 & 0.45 & 0.60 \\
3 & -0.11 & 1.07 & 0.02 & 0.27 & 0.36 \\
4 & -0.07 & 0.53 & 0.01 & 0.16 & 0.23 \\
5 & -0.04 & 0.27 & 0.00 & 0.10 & 0.14 \\
6 & -0.02 & 0.13 & 0.00 & 0.07 & 0.10 \\
7 & -0.01 & 0.05 & 0.00 & 0.05 & 0.07 \\
8 & -0.00 & 0.01 & 0.00 & 0.04 & 0.05 \\
9 & 0.00 & -0.01 & 0 & 0.03 & 0.04 \\
\hline
\end{tabular}

Panel C: Real quantities

\begin{tabular}{rrrrrrr}
\hline & $\mathrm{C}$ & $\mathrm{I}$ & $\mathrm{Y}$ & $n_{f}$ & $n_{b}$ & $l_{1}$ \\
\hline 0 & 0.39 & 6.12 & 1.77 & 0.64 & 1.75 & 0.36 \\
1 & 0.23 & 3.04 & 0.91 & 0.32 & 0.99 & 0.18 \\
2 & 0.15 & 1.49 & 0.47 & 0.15 & 0.48 & 0.09 \\
3 & 0.10 & 0.72 & 0.25 & 0.07 & 0.21 & 0.04 \\
4 & 0.08 & 0.33 & 0.14 & 0.03 & 0.09 & 0.02 \\
5 & 0.07 & 0.14 & 0.09 & 0.01 & 0.03 & 0.00 \\
6 & 0.06 & 0.04 & 0.06 & -0.00 & 0.00 & -0.00 \\
7 & 0.06 & -0.01 & 0.04 & -0.01 & -0.01 & -0.00 \\
8 & 0.06 & -0.03 & 0.04 & -0.01 & -0.01 & -0.01 \\
9 & 0.06 & -0.05 & 0.03 & -0.01 & -0.01 & -0.01 \\
\hline
\end{tabular}

${ }^{*}$ Response to a one percent innovation in $x_{f}$, where $b_{1}, b_{2}, \rho$ are as in table 1. Entries for $r_{a}$, $r_{b}$ and $\pi$ report the percentage point deviation of these variables from their unshocked steady state path. All other entries report percent deviations from their unshocked steady state paths. 
Table 7a: Cyclical behavior of the U.S. economy

1954:1 - 1988:2, sample interval: quarterly

Correlation of $x_{t}$ with output $t_{t-k}$

\begin{tabular}{lllllll}
\hline Variables $x$ & Std. Dev. & $k=-2$ & $k=-1$ & $k=0$ & $k=1$ & $k=2$ \\
\hline Gross national product & $1.74 \%$ & 0.63 & 0.85 & 1.00 & 0.85 & 0.63 \\
Consumption expenditures & 0.73 & 0.71 & 0.81 & 0.81 & 0.66 & 0.45 \\
Services \& nondurable goods & 0.49 & 0.67 & 0.76 & 0.76 & 0.63 & 0.47 \\
Durable goods & 2.92 & 0.65 & 0.74 & 0.77 & 0.60 & 0.37 \\
Fixed investment & 3.17 & 0.65 & 0.83 & 0.90 & 0.81 & 0.60 \\
Hours (household survey) & 0.86 & 0.44 & 0.68 & 0.86 & 0.86 & 0.75 \\
Hours (establishment survey) & 0.97 & 0.39 & 0.67 & 0.88 & 0.92 & 0.81 \\
Hours per worker & 0.32 & 0.48 & 0.64 & 0.69 & 0.58 & 0.43 \\
Civilian employment & 0.62 & 0.36 & 0.61 & 0.82 & 0.89 & 0.82 \\
GNP/Hours (household) & 0.52 & 0.49 & 0.51 & 0.51 & 0.21 & -0.03 \\
GNP/Hours (establishment) & 0.48 & 0.53 & 0.43 & 0.31 & -0.08 & -0.32 \\
\hline
\end{tabular}

Data source: Kydland and Prescott (1991), table 3. Data have been logged and hp filtered. Column1 reports standard deviations relative to the standard deviation of output.

Table 7b: Cyclical behavior of the model economy Correlation of $x_{t}$ with output $t_{t-k}$

\begin{tabular}{lllllll}
\hline Variables $x$ & Std. Dev. & $k=-2$ & $k=-1$ & $k=0$ & $k=1$ & $k=2$ \\
\hline Gross national product & $1.77 \%$ & 0.08 & 0.38 & 1.00 & 0.38 & 0.08 \\
Consumption & 0.22 & 0.01 & 0.33 & 0.99 & 0.44 & 0.15 \\
Fixed investment & 3.47 & 0.09 & 0.39 & 1.00 & 0.37 & 0.06 \\
Hours & 0.58 & 0.09 & 0.39 & 0.99 & 0.37 & 0.06 \\
Hours per worker & 0.21 & 0.09 & 0.39 & 0.99 & 0.37 & 0.06 \\
Employment & 0.37 & 0.09 & 0.39 & 0.99 & 0.37 & 0.06 \\
GNP/Hours & 0.43 & 0.06 & 0.36 & 0.99 & 0.39 & 0.10 \\
\hline
\end{tabular}

* Data have been logged and hp filtered. Sample interval: model period (one-half sampling interval). Column 1 reports standard deviations relative to the standard deviation of output. 
Table 8: Correlation Properties: Money, Output and Interest Rates Panel A: U.S. data Correlation of $r_{a t}$ with:

\begin{tabular}{lrrrrr}
\hline & $x_{t+2}$ & $x_{t+1}$ & $x_{t}$ & $x_{t-1}$ & $x_{t-2}$ \\
\hline Output & -0.18 & 0.09 & 0.36 & 0.54 & 0.59 \\
M1 & -0.32 & -0.24 & -0.05 & 0.14 & 0.24 \\
Base & -0.19 & -0.11 & 0.06 & 0.21 & 0.27 \\
NBR & -0.34 & -0.48 & -0.55 & -0.41 & -0.22 \\
\hline
\end{tabular}

* Monetary data have been logged and all data have been hp filtered. Sample interval: quarterly.

Panel B: Baseline model Correlation of $r_{a t}$ with:

\begin{tabular}{lrrrrr}
\hline & $x_{t+2}$ & $x_{t+1}$ & $x_{t}$ & $x_{t-1}$ & $x_{t-2}$ \\
\hline Output & 0.02 & 0.15 & 0.36 & 0.48 & 0.11 \\
M1 & -0.08 & -0.06 & 0.03 & 0.32 & 0.15 \\
Base & -0.24 & -0.22 & 0.00 & 0.41 & 0.29 \\
Reserves & -0.02 & -0.03 & 0.02 & 0.29 & 0.10 \\
NBR & 0.06 & -0.11 & -0.58 & -0.44 & -0.12 \\
\hline
\end{tabular}

* Monetary data have been logged and all data have been hp filtered. Sample interval: model period.

Panel C: Baseline model, no monetary accommodation Correlation of $r_{a t}$ with:

\begin{tabular}{lrrrrr}
\hline & $x_{t+2}$ & $x_{t+1}$ & $x_{t}$ & $x_{t-1}$ & $x_{t-2}$ \\
\hline Output & 0.16 & 0.50 & 0.89 & 0.28 & -0.11 \\
M1 & 0.19 & 0.33 & 0.37 & 0.04 & -0.09 \\
Base & -0.15 & -0.18 & -0.19 & -0.03 & 0.11 \\
Reserves & 0.34 & 0.35 & -0.14 & -0.24 & -0.15 \\
NBR & 0.34 & 0.35 & -0.14 & -0.24 & -0.15 \\
\hline
\end{tabular}

* Monetary data have been logged and all data have been hp filtered. Sample interval: model period.

Panel D: Baseline model, monetary accommodation, no limited participation Correlation of $r_{a t}$ with:

\begin{tabular}{lrrrrr}
\hline & $x_{t+2}$ & $x_{t+1}$ & $x_{t}$ & $x_{t-1}$ & $x_{t-2}$ \\
\hline Output & 0.02 & 0.33 & 0.96 & 0.59 & 0.24 \\
M1 & 0.00 & 0.29 & 0.93 & 0.56 & 0.23 \\
Base & 0.10 & 0.09 & 0.75 & 0.48 & 0.21 \\
Reserves & 0.00 & 0.31 & 0.96 & 0.59 & 0.25 \\
NBR & 0.44 & 0.88 & 0.79 & 0.37 & 0.08 \\
\hline
\end{tabular}

* Monetary data have been logged and all data have been hp filtered. Sample interval: model period. 
Table 9: Correlation Properties, Money and Output

Panel A: U.S. data

Correlation of $x_{t}$ with output $t_{t-k}$

\begin{tabular}{lrrrrr}
\hline & $k=-2$ & $k=-1$ & $k=0$ & $k=1$ & $k=2$ \\
\hline Ml & 0.33 & 0.34 & 0.29 & 0.18 & 0.10 \\
Base & 0.37 & 0.39 & 0.34 & 0.26 & 0.20 \\
NBR & 0.10 & -0.06 & -0.22 & -0.32 & -0.34 \\
\hline
\end{tabular}

* All variables have been logged and hp filtered. Sample interval: quarterly.

Panel B: Baseline model

Correlation of $x_{t}$ with output $\mathrm{t}_{t-k}$

\begin{tabular}{lrrrrr}
\hline & $k=-2$ & $k=-1$ & $k=0$ & $k=1$ & $k=2$ \\
\hline M1 & 0.06 & 0.34 & 0.92 & 0.32 & 0.07 \\
Base & 0.08 & 0.33 & 0.84 & 0.15 & -0.05 \\
Reserves & 0.08 & 0.35 & 0.94 & 0.29 & 0.06 \\
NBR & -0.07 & -0.02 & 0.16 & 0.35 & 0.30 \\
\hline
\end{tabular}

* All variables have been logged and hp filtered. Sample interval: model period. 
Figure 1
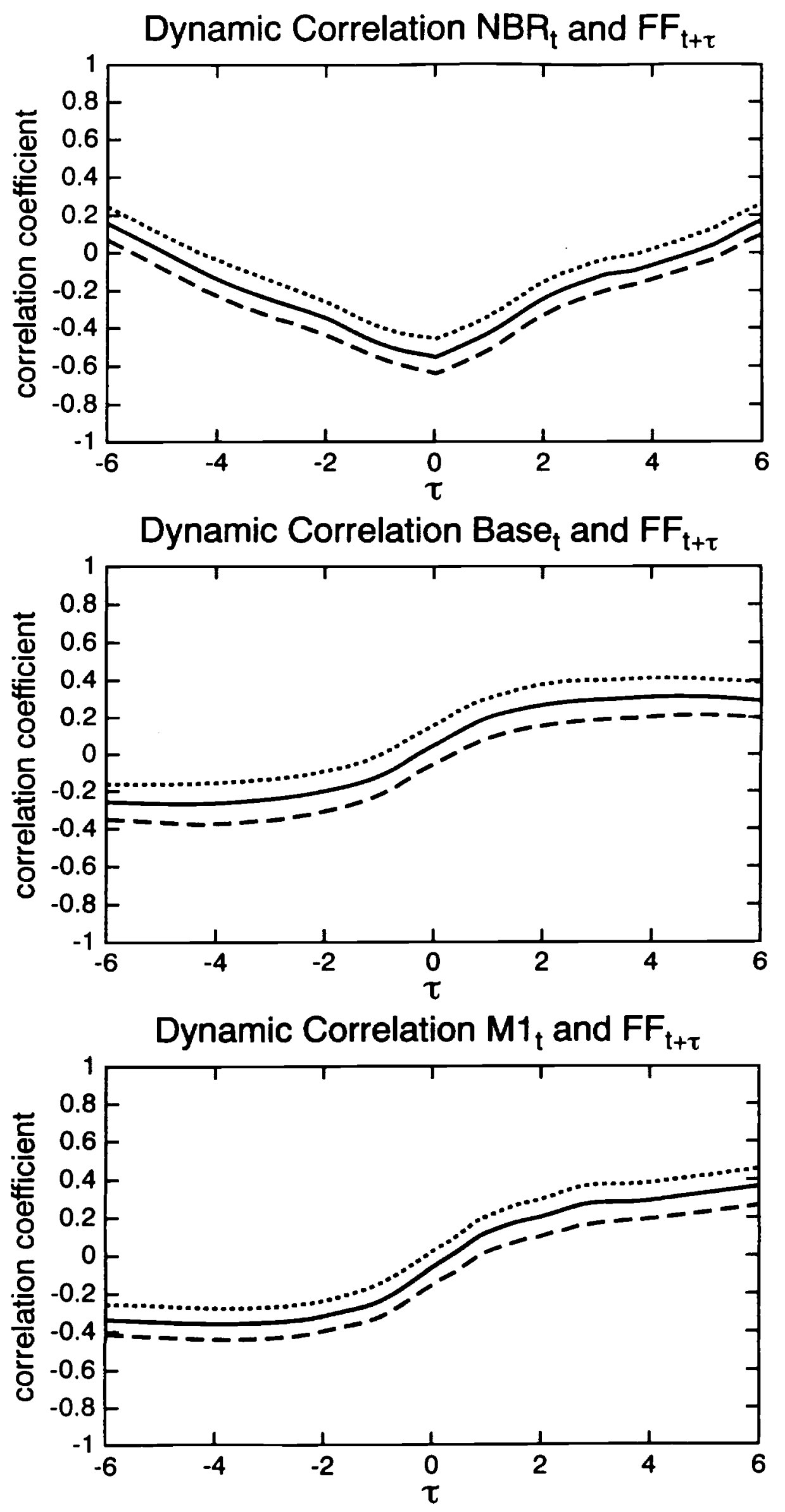
Figure 2
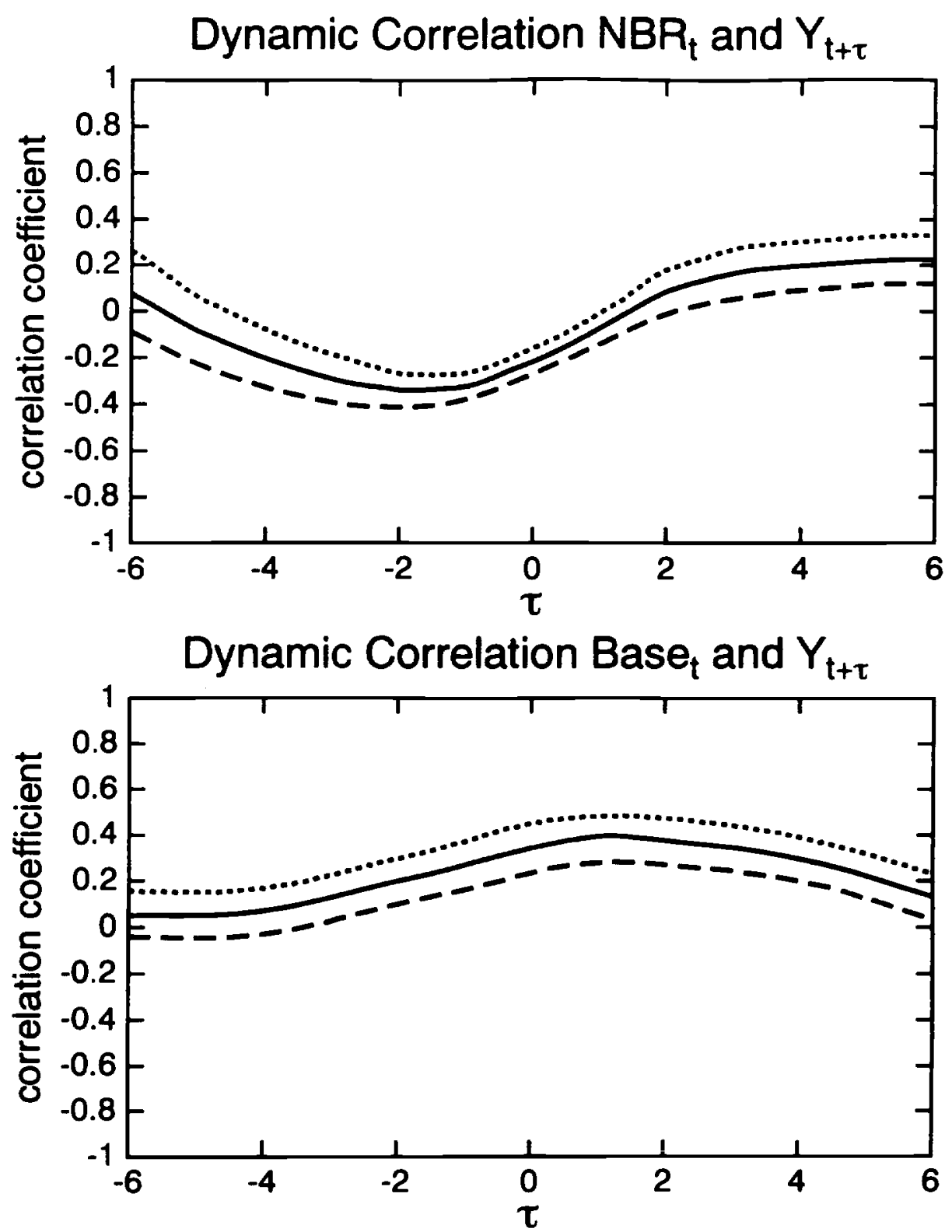

Dynamic Correlation $\mathrm{M}_{\mathrm{t}}$ and $\mathrm{Y}_{\mathrm{t}+\tau}$

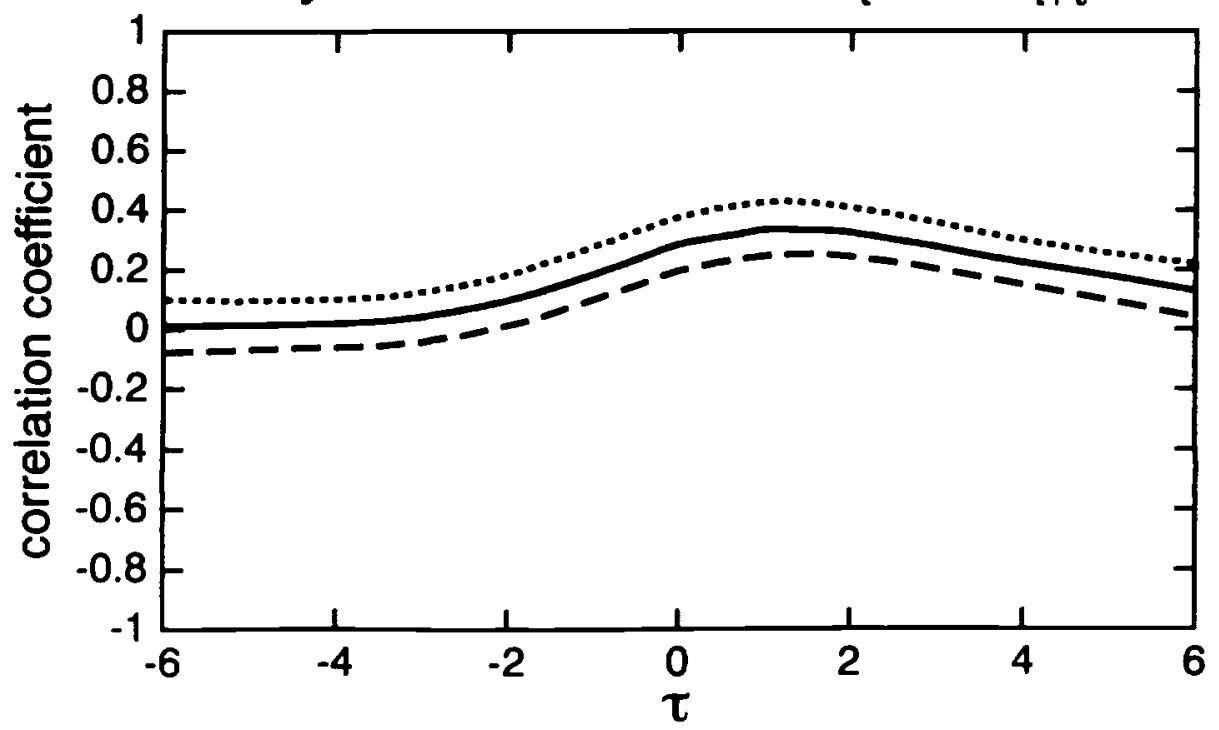


Figure 3

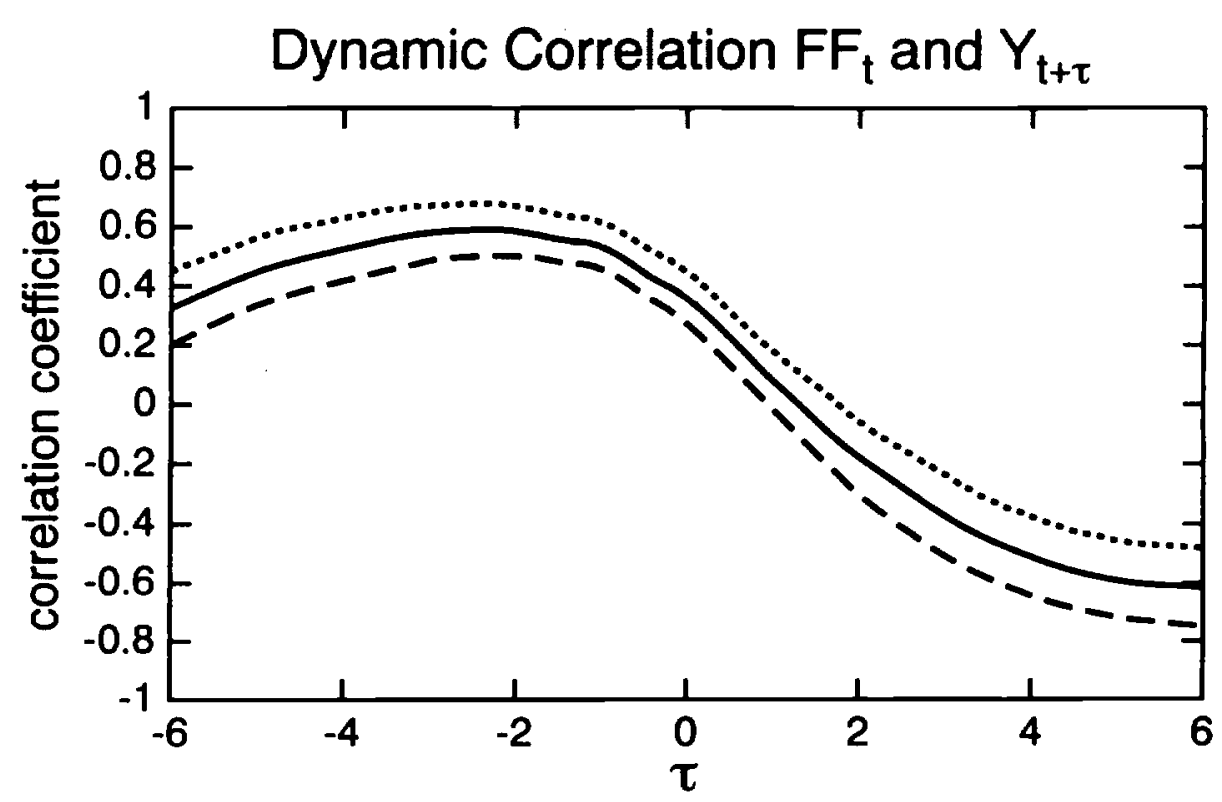

